VATT Working Papers 118

\title{
Anatomy of public procurement
}

Jan Jääskeläinen

Janne Tukiainen 


\section{VATT WORKING PAPERS}

\section{8 \\ Anatomy of public procurement}

Jan Jääskeläinen

Janne Tukiainen 
Jan Jääskeläinen, Aalto University School of Business, Department of Economics, and Helsinki GSE, Ekonominaukio 1, Espoo, P.O. Box 21210 FI00076 Aalto, jan.jaaskelainen@aalto.fi, Tel. +358505423792.

Janne Tukiainen, Corresponding author. Department of Government, London School of Economics and Political Science, Houghton Street, London WC2A 2AE, United Kingdom, and VATT Institute for Economic Research, Arkadiankatu 7, P.O.Box 1279, Helsinki, FI-00101, janne.tukiainen@vatt.fi, Tel. +358295519451 .

We thank the seminar and conference participants at FEA 2019, VATT, and the Mannheim Public Procurement workshop for the useful discussions. We also thank Zareh Asatryan, Sebastian Blesse, Kirsi-Maria Halonen, Vitalijs Jascisens, Mika Kortelainen, Jorma Lamminmäki, Matti Liski, Oskari Nokso-Koivisto, Giancarlo Spagnolo, Otto Toivanen and Iivo Vehviläinen for their helpful comments. We are grateful to the Aalto Economic Institute for funding and negotiating the public procurement data, and to Cloudia Oy for sharing it and for providing their expertise. We thank the Yrjö Jahnsson Foundation for funding the Statistics Finland data. Jan Jääskeläinen also thanks Yrjö Jahnsson Foundation for the financial support.

ISBN 978-952-274-236-0 (PDF)

ISSN 1798-0291 (PDF)

Valtion taloudellinen tutkimuskeskus

VATT Institute for Economic Research

Arkadiankatu 7, 00100 Helsinki, Finland

Helsinki, April 2019 


\title{
Anatomy of public procurement
}

\section{VATT Institute for Economic Research VATT Working Papers 118/2019}

Jan Jääskeläinen - Janne Tukiainen

\begin{abstract}
We provide novel stylized facts about competition, bidding, entry and bidders across a wide spectrum of public procurement auctions using comprehensive and rich Finnish data. Competition for publicly procured contracts is relatively low with a median bidder count of two (three conditional on receiving any bids). Bidders typically are very heterogeneous in size, which likely limits competition further. Competition seems to work roughly as expected as on average (standardized) bids mainly decrease with the number of actual and potential bidders. Using information on registrations as a good proxy for potential bidders, we show that the ratio of actual to potential bidders increases with the number of actual bidders. We also show that being present in the contracting authority's municipality or province correlates positively with registering, entry (bidding) and winning, but other firm characteristics matter less. While attracting more competition by means of contract and auction rule design is a desirable policy goal and we show suggestive evidence that the use of scoring rule can be an entry barrier, increasing competition may be in practice difficult. Therefore, reservation prices may be a more useful policy tool to alleviate issues associated with the lack of competition.
\end{abstract}

Key words: Competition, Entry, Public Procurement

JEL classes: D44, H57, H76, L11 


\section{Introduction}

In many countries, a large share of public sector purchases are implemented via public procurement (PP). For example, in the OECD countries PP is estimated to account for about $12 \%$ of GDP. ${ }^{1}$ Adopting PP is often seen as addressing both issues related to the lack of incentives, inefficiencies and rent-seeking involved in in-house production by the public sector (e.g. Alchian \& Demsetz 1972 and Niskanen 1971), and various market imperfections arising in private markets producing public goods. However, recently policy makers in the EU have been increasingly worried that PP does not work as it should due to a severe lack of competition. For example, according to the European Commission (2017), "Public procurement relies on open competition to deliver the best value for public money. This competitive process is either not present or it is losing intensity. Between 2006 and 2016, the number of tenders with only one bid has grown from $17 \%$ to $30 \%$. The average number of offers per tender fell from five to three in the same period."

Despite the pressing policy need to understand the implications of this lack of competition, and the reasons for it, as well as the possible remedies, the existing evidence is very limited in scope. We seem to be missing a comprehensive picture regarding some of the very basic and fundamental questions about the anatomy of public procurement in any country. Does PP work by and large as intended? How extensive is the lack of competition and how does it vary across industries, procurer type, and the applied auction mechanisms? Does competition work as the auctioneer would like? How can one attract more potential bidders? What type of potential bidders bid and what type abstain, and can entry be influenced by the auction or contract design?

We leverage rich and wide data to provide comprehensive descriptive evidence on these questions in Finland. Finland is an interesting case for such an analysis as a standard auction mechanism (first-price sealed-bid) is in use, and the regulatory framework follows the standards adopted in the EU. Our data contain all types of public procurers (central, regional and local governments, and other types of public authorities conducting PP such as public universities, state church, municipal co-operations) and cover all industries, and throughout the country. We have information on the invitations to tender (ITT) and all the bids and registrations, which we argue to be a very good proxy for potential bidders, which allows for detailed analysis of

\footnotetext{
${ }^{1}$ Source: http://www.oecd.org/gov/public-procurement/ accessed on February 3, 2019.
} 
entry choices. We also have detailed information on all the participating and potential bidders.

The reason for the lack of prior evidence is that most of the applications using PP data usually analyze special cases, i.e. they use data from a single type of services or goods, or a single type of contracting authority (henceforth we use the term procurer). In cases where more comprehensive data are available and used, often the auction mechanism is non-standard (see Ferraz et al. 2016 for Brazil and Lee 2017 for Korea), or the data are limited in other ways, such as lacking information on all the bids (e.g. Decarolis et al. 2018 for the US). The richest data (aside ours) concern Lithuania (Baltrunaite 2018) and Russia (Best et al. 2018 and Vitalijs 2017), but even in those, and in all the large data sets we are aware of, information on (or a good proxy for) potential bidders is missing. In Table 2, we provide more details of the literature and the available data. In addition to these data limitations, research questions are usually focused on specific topics rather than aimed at providing a descriptive overview of the data.

We make several key observations. First, there seems to be a serious lack of competition also in Finnish PP across industries and procurers, with a median number of actual bidders of only two. This means that for more than half of the auctions, there are either no bidders, a monopoly bidder or duopoly bidders. Even conditional on attracting at least one bidder, the level of competition is low with the median number of actual bidders being three. The issues associated with the lack of competition are likely further exacerbated by the large heterogeneity in size (turnover and employment) between the bidders that we observe. The lack of competition is an issue across all industries and different contracting authorities.

Second, we argue that the lack of competition is likely to be a problem for procuring goods and services as we show competition (both the number of actual and potential bidders) to have by and large the desired correlations with the standardized price measures (win margin, and difference between the expected and realized price). Increasing competition has only a minor influence after six or more bidders participate, but less than $10 \%$ of the invitations to tender have more than six bidders. This association between competition and prices is not as trivial as would intuitively seem despite standard auction theory (Bulow \& Klemperer 1996, Klemperer 2000) arguing that attracting enough competition is crucial in making public procurement auctions work in getting high-quality goods and services at reasonable prices. The reason is that the "Common values effect" (Bulow et al. 1999, Hong \& Shum 2002), the "Affiliation effect" (Pinkse \& Tan 2005, Hubbard et al. 2012), and the "Entry effect" (Li \& Zheng 2009) 
may limit the benefits of competition or even reverse the relationship between prices and the number of bidders. We describe these mechanisms later and argue that they may explain why the association between competition and standardized prices is not always monotonic.

Third, our data offer a unique opportunity to understand the reasons behind the lack of competition, because we observe the universe of potential bidders. We show that the lack of competition arises both from the lack of potential bidders and from entry costs that prevent potential bidders from submitting bids. This indicates a need to both design the contracts in such a way that they appeal to more firms, and to design both the contracts and the bidding process so that it is simple to calculate production costs and submit bids. One possible avenue is a careful consideration of how to contract for quality as we show that the use of scoring auctions is associated with lower entry probabilities. However, given that auction rules overall do not correlate much with the number of bidders, and given that based on our analysis entry costs seem to be more about firms needing to calculate their production costs rather than about bid preparation costs, the auctioneer seems to have somewhat limited tools to attract more bidders. Moreover, the most important firm characteristic that predicts entry is firm location, and that is beyond the control of the procurer. Therefore, a more rigorous use of reservation prices should be implemented to limit the high prices that the lack of competition leads to (Myerson 1981, Gentry \& Li 2014 and Vitalijs 2017).

Our analysis contributes to the recent surge of literature in policy-relevant PP questions. These topics include for example, corruption (Bandiera et al. 2009, Mironov \& Zhuravskaya 2016), favoritism (Hyytinen et al. 2018), various political economy concerns (Boas et al. 2014, Baltrunaite 2018, Ruiz 2018, Gulzar et al. 2018), (incomplete) contracting on quality (Asker \& Cantillon 2008, Asker \& Cantillon 2010, Lewis \& Bajari 2011, Lewis \& Bajari 2014, Hart et al. 1997), litigation concerns (Coviello et al. 2018), fiscal policy goals (Balat 2017, Ferraz et al. 2016, Lee 2017), and the nature and amount of competition (Hong \& Shum 2002, Li \& Zheng 2009, Kang \& Miller 2017). To our knowledge, we are the first to provide a comprehensive description of how competition and entry work in PP.

In the next Section, we describe how we constructed the data and describe them. In particular we analyze how representative they are. In Section 3, we analyze the extent and implications of competition. In Section 4, we analyze the role of entry in the lack of competition. Section 5 provides more information on the bidders, in particular on the nature of bidder asymmetry. We conclude in Section 6. 


\section{Institutional setting and data}

\subsection{Institutional setting}

The Act on Public and Concession Contracts (1397/2016) in Finland is based on EU regulations and dictates that all purchases made by municipalities, government entities and state-owned enterprises need to follow a predetermined procurement procedure. The only exceptions are purchases that are under the government-set minimum threshold values. This threshold is 60 000 euro for most goods and services, 150000 euro for construction works, and 400000 euro for social and health care services. ${ }^{2}$

The procurement procedure is as follows. When a public entity decides to make a purchase that is over the threshold value, it must advertise the contract notice and the invitation to tender in a publicly run electronic notice board called Hilma. On Hilma, firms can opt to register free of charge for more information about the Invitation to Tender (henceforth ITT) from a source provided by the buyer. The ITT must include all information about the purchase, thus ensuring that complete information is available to all potential bidders. The invitation also sets the timeline for the procurement procedure and informs bidders about the allocation rule.

Two different allocation rules are used in public procurement. ${ }^{3}$ The first chooses the lowest price from all the bidders who fulfill the minimum (quality) requirements. The second rule allocates the purchase to the "most economically advantageous bidder". In practice, this means using a scoring rule to evaluate quality criteria. In the majority of cases, the weight of the quality score is $50 \%$ or less, with the remaining weight being allocated to the price. All bids in our sample are submitted as sealed bids and the winning bidder pays the amount bid. ${ }^{4}$

\subsection{Procurement data}

We use data from public procurement auctions held in Finland between June 2010 - September 2017. Nowadays, the majority of Finnish public sector entities use electronic procurement

\footnotetext{
${ }^{2}$ Some of the threshold values were increased on 1.1.2017. The values from the previous period were 30000 euro for most goods and services and 100000 euro for social and health care services.

${ }^{3}$ There is also a third rule which allocates based on producer costs, but it is used in less than 0.1 percent of Finnish public procurement.

${ }^{4}$ In some recent and very rare cases an ascending electronic auction format has been used.
} 
software provided by a single private firm Cloudia Oy to conduct their procurement auctions with Cloudia's market share being almost 90\%. This expansion has been rapid as their software was introduced only in 2010. They benefited especially from a recent regulation stating that starting from January 2018 all public procurement must take place via electronic platforms. From 2010, a gradually increasing amount of municipalities and other public sector agents have started using their platform. This means that a large part of our data is from recent years.

Our data contain over 18000 ITTs with at least one bidder registration, 275000 auctions and 705000 bids. $^{5}$ Invitations to tender often contain several separate auctions for which bidders submit individual bids. For example, an invitation to tender may be about office stationery, and the individual auctions within it about paper, pens etc. Currently the latest full year in our data (2016) contains about $30 \%$ of all the ITTs for that year (in Hilma), totaling 5.3 billion euro in expected costs. ${ }^{6}$ Procurers are not forced to disclose the expected cost, hence it is missing for approximately $25 \%$ of the invitations to tender. We are in the process of extending the data to include the most recent year (2018) with potentially even up to almost $90 \%$ of municipal public procurement auctions in Finland.

The industry classifications can be obtained from CPV classification codes. ${ }^{7}$ Moreover, we have the procurer's written description of the invitation to tender as well as the details of each individual auction, which allows us to analyze procurement at a very detailed level. Furthermore, we can use information on the bidders (see next subsection) to infer the industry.

The Cloudia procurement data are generated in three steps. First, a procurer makes a decision to procure something and chooses how to conduct the procurement. At this stage most of the procurement process related data are created, including all the ITT-specific variables. These are the objects of the procurement, the engineer-estimated cost, the allocation rule (scoring vs. price only), and whether bidders are allowed to bid on a subset of auctions. We

\footnotetext{
${ }^{5}$ We omit ITTs with zero registrations as for them we cannot disentangle whether it is a mistake or some kind of a test in the Cloudia system. Therefore, the real extent of competition may be even lower than we document.

${ }^{6}$ We cross-reference our data with Hilma to ensure there are no pre- or post-announcements which are not meant for bidding or registrations. We also exclude all such announcements from the Hilma database when comparing the two sets of data.

${ }^{7}$ The common procurement vocabulary (CPV) establishes a single classification system for public procurement in the EU aimed at standardizing the references used by contracting authorities and entities to describe procurement contracts.
} 
refer to this option of dividing the contract into separate lots as partial procurement.

In the second step, potential bidders opt-in to an invitation to tender by registering for the ITT in the Cloudia system via a link in Hilma. Based on our discussions with several civil servants who conduct public procurement and Cloudia employees, registration is a very good proxy for being a potential bidder. Registering requires only a very small (but non-zero) amount of effort, and allows bidders to access further information about the tender that is only available to registered firms. Registering firms then choose whether to actually bid in the auctions concerned. It is not possible to bid without registering. We have data on all the firms that have registered in an ITT and all the bids submitted in the auctions. We also observe auctions where no bids were submitted.

In the final step, the contracting authority awards a contract to one or several economic operators that have submitted a bid. We have the information on the chosen winner(s), which is important in the case of scoring auctions, where sometimes the lowest price doesn't win. So far, we do not have detailed information on what kind of scoring rule has been used or how the bids and quality characteristics are translated into scores. Possibly some of that information could be constructed from the database using text analysis methods.

\section{$2.3 \quad$ Firm data}

We merge the procurement data with detailed firm-level data and with Finnish Longitudinal Employer-Employee Data (FLEED) obtained from Statistics Finland. These data contain information on all the approximately 300000 Finnish firms and their employees up to and including the year 2016.

The firm data contain all the information found in the firms' financial statements as well as information on the municipalities where the firm is registered for business. The latter allows us to analyze the importance of geographical presence in public procurement. All the firm data are collected by Statistics Finland on a yearly basis.

The FLEED also contains information on the firms' employees. We observe employees' levels of education, salaries and several other personal characteristics such as the municipality where the employee lives. We also observe employment and unemployment on a monthly basis. This information will be utilized in future work.

All the data are matched using the business identity codes that exist for all Finnish com- 
panies. When identifying unregistered bidders from the same industries, we first look at the most common industry classification among the firms that have registered to an invitation to tender, and then match unregistered firms in the same industry as potential registers for that ITT.

\subsection{Descriptive statistics}

The most commonly procured goods and services in our data, as well as their cumulative expected costs, can be seen in Figure 1. In terms of the number of tenders, construction is the most common. There are also many different service and equipment categories with a lot of tenders. Social housing service contracts are extremely valuable even if there are not that many of them. Social and health care contracts are both valuable and numerous.

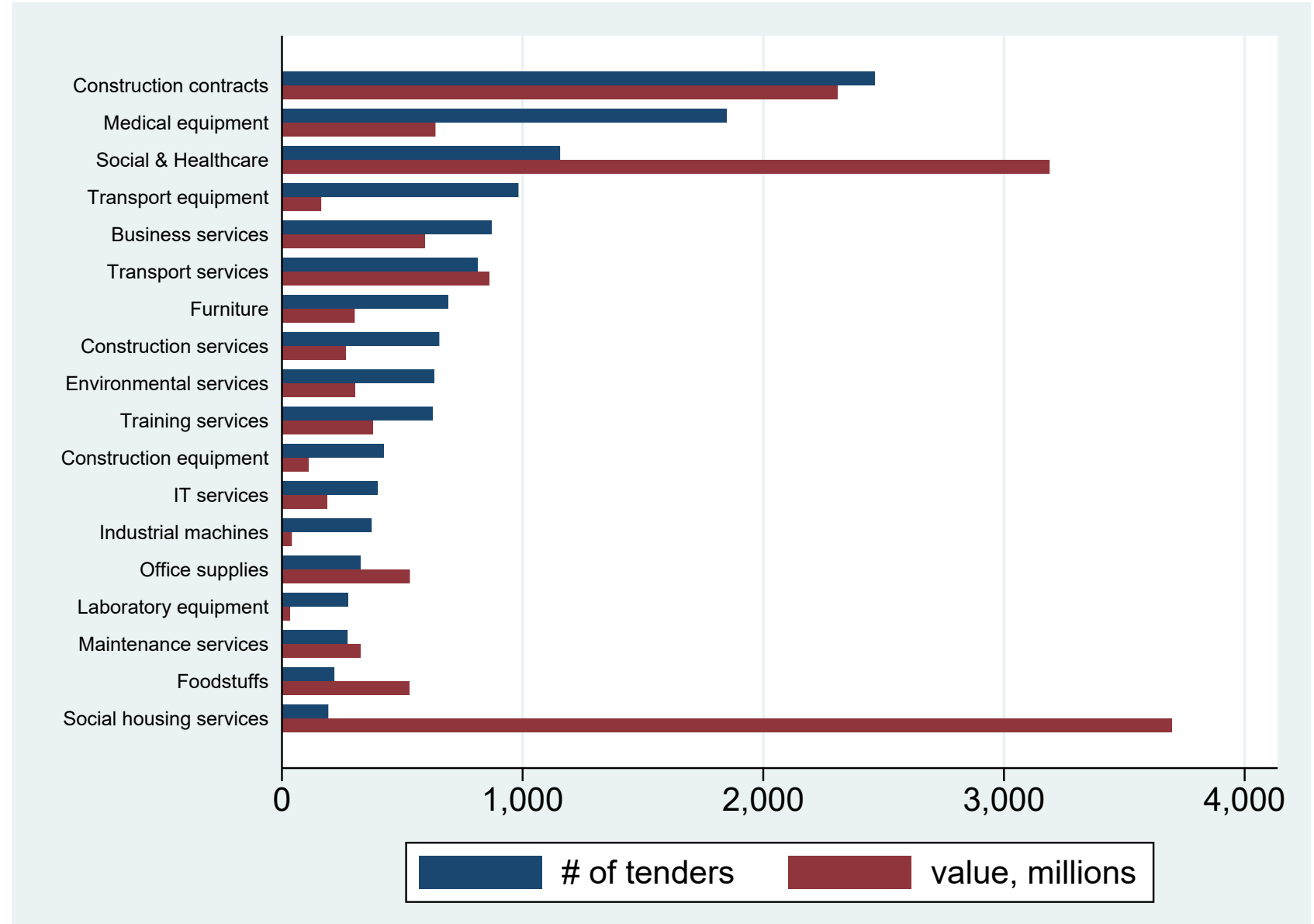

Figure 1: Number of invitations to tender and sum of their expected values.

Notes: Number of invitations to tender in our sample, presented for the commonly procuring industries. The sum of expected values is calculated using engineer estimates provided by the procurer. Engineer estimates are available for only $75 \%$ of the ITTs. 
The descriptive statistics on the invitations to tender and the choices made by the procurer are presented in Table 1 . The most costly tenders are in the social and health care sector where the median expected cost of procurement is 680000 euro, about three times the amount in the construction sector, which ranks second at 230000 euro. Social and health care ITTs have the highest share of partial procurement at $45 \%$. Scoring is most common in the Goods category. Procurer size is measured as the expected value of tenders invited by the given procurer in the year 2016. The procurer size distributions do not vary much across the four industries. However, there are larger differences between procurer size when we compare various public sector branches to each other. Central government procurers are the largest, and municipalities and health care districts the smallest.

To understand how representative our data are of the entire Finnish public procurement scene, we complement and cross-reference our data with Hilma, which contains all Finnish public procurement, but lacks the detailed information that our data contain. In the left-hand graph in Figure 2, we show that the distribution of the count of ITTs across industries is fairly similar in Hilma and our sample. Depending on the industry, our sample covers 7 - $25 \%$ of all procurement in 2010 - 2017. Our data get richer in later years, roughly doubling the share of procurement covered by the year 2016 with the most representative industries reaching $50 \%$ coverage (see Table 13 in the Appendix). A comparison provided in the right-hand graph in Figure 2 shows that the representation of industries in the year 2016 is quite similar to earlier years, implying that the sample is representative across industries. The reason for this was explained to us by Cloudia, who state that typically they get all or most of the PP run by a municipality or other government body, or none at all. Thus the sample is representative across industries but some municipalities are missing completely from the data. Based on Table 14 in the Appendix, there is some selection based on the use of the scoring rule, but the data sets appear to be balanced on the expected cost of procurement. 
Table 1: Descriptive statistics on procurers and ITTs

\begin{tabular}{|c|c|c|c|c|c|}
\hline \multicolumn{2}{|l|}{ Panel A } & \multirow[b]{2}{*}{ Size of procurer } & \multirow[b]{2}{*}{ Est. cost } & \multirow[b]{2}{*}{ Partial } & \multirow[b]{2}{*}{ Scoring } \\
\hline & & & & & \\
\hline \multirow[t]{3}{*}{ Construction } & mean & 129,032 & 808.89 & 0.14 & 0.23 \\
\hline & se(mean) & 2,848 & 39.44 & 0.01 & 0.01 \\
\hline & median & 54,260 & 245 & & \\
\hline \multirow[t]{3}{*}{ Goods } & mean & 151,579 & 616.02 & 0.31 & 0.57 \\
\hline & se(mean) & 2,507 & 42.42 & 0.01 & 0.01 \\
\hline & median & 64,532 & 100 & & \\
\hline \multirow[t]{3}{*}{ Services } & mean & 209,734 & $1,094.41$ & 0.26 & 0.52 \\
\hline & se(mean) & 3,582 & 71.87 & 0.01 & 0.01 \\
\hline & median & 91,599 & 150 & & \\
\hline \multirow[t]{3}{*}{ Social \& Health care } & mean & 176,624 & $5,223.49$ & 0.45 & 0.38 \\
\hline & se(mean) & 6,007 & 532.70 & 0.01 & 0.02 \\
\hline & median & 68,493 & 680 & & \\
\hline \multirow[t]{2}{*}{ Panel B } & & & & & \\
\hline & & Size of procurer & Est. cost & Partial & Scoring \\
\hline \multirow[t]{3}{*}{ Government } & mean & 281,999 & $3,073.00$ & 0.18 & 0.61 \\
\hline & se(mean) & 6,735 & 297.34 & 0.01 & 0.01 \\
\hline & median & 283,572 & 220 & & \\
\hline \multirow[t]{3}{*}{ Health care districts } & mean & 76,910 & 736.85 & 0.32 & 0.66 \\
\hline & se(mean) & 2,639 & 72.15 & 0.01 & 0.01 \\
\hline & median & 37,980 & 120 & & \\
\hline \multirow[t]{3}{*}{ Joint municipalities } & mean & 147,395 & $1,967.80$ & 0.34 & 0.42 \\
\hline & se(mean) & 1,769 & 309.86 & 0.01 & 0.01 \\
\hline & median & 200,552 & 150 & & \\
\hline \multirow[t]{3}{*}{ Municipalities } & mean & 149,961 & $1,160.15$ & 0.25 & 0.43 \\
\hline & se(mean) & 1,869 & 67.62 & 0 & 0.01 \\
\hline & median & 51,985 & 160 & & \\
\hline
\end{tabular}

Notes: Descriptive statistics are categorized by industry in panel A and by procurer type in Panel B. Size of procurer is calculated by taking a sum of engineer estimates for all ITTs of a procurer in the latest full year (2016). Estimated cost is an engineer estimate announced by the procurer when posting an ITT. Estimated cost is available for approximately $70 \%$ of ITTs. Partial refers to share of ITTs that were split into smaller, separately awarded contracts. Scoring refers to share of ITTs which were awarded using a scoring rule. Both size and estimated costs are reported in thousands of euro. Unit is ITT. 
(1) Number of ITTs

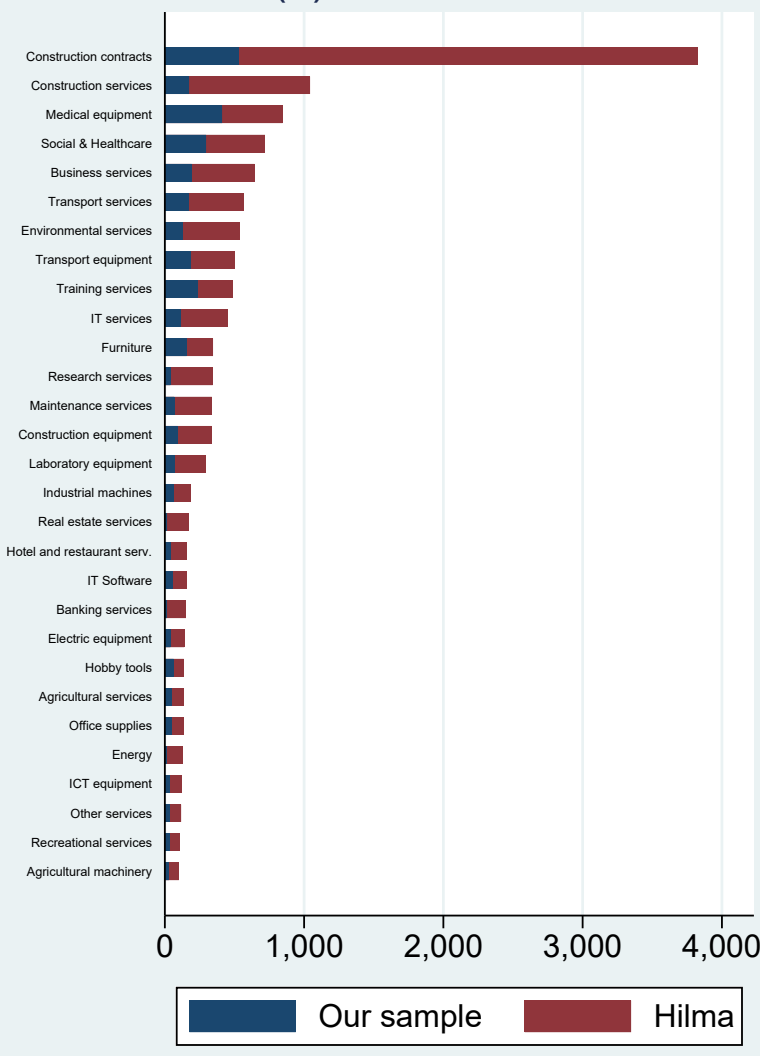

(2) Share

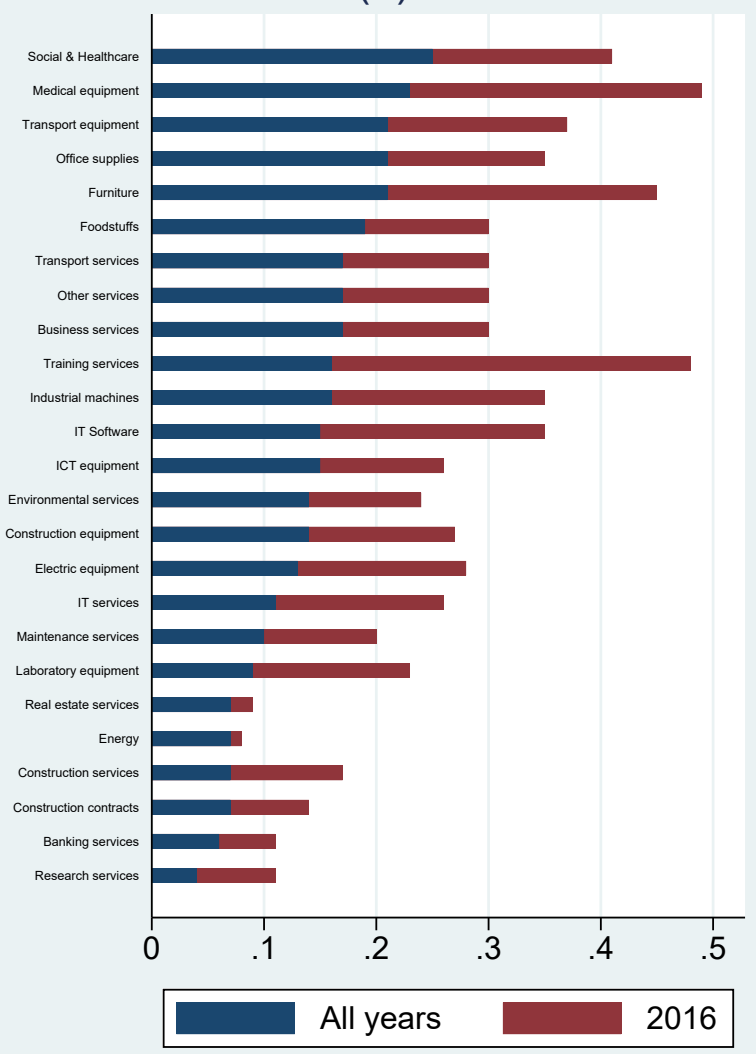

Figure 2: Comparison of our sample to Hilma database

Notes: Graph (1) presents the number of invitations to tender in our sample and the Hilma database in the year 2016. Graph (2) presents the share of our sample compared to all public procurement in Finland in the whole sample period and its most representative year (2016). Hilma contains information on all public procurement in Finland. Categories are based on the CPV classification.

\subsection{Comparison with related studies}

In Table 2, we survey recent studies using somewhat similar large public procurement databases as we do. We describe the country in question, the auction mechanisms applied, the industries and procurers that the data contain, and which bids the data have information on. We also document that none of these data have information on the number of potential bidders $(N)$ or their characteristics. In addition to this limitation, these data sets have other limitations relative to our case to a varying degree. For some (but not all) parts, the analysis we provide cannot be replicated with these other existing comprehensive data sets, at least at the moment. 
Table 2: Survey of public procurement datasets from related studies

\begin{tabular}{|c|c|c|c|c|c|c|}
\hline Related papers & Country & Mechanism & Industry & Procurer & Bids & Registrations \\
\hline Baltrunaite 2018 & Lithuania & first price & all & $\begin{array}{l}\text { whole public } \\
\text { sector }\end{array}$ & all & no \\
\hline $\begin{array}{l}\text { Best et al. 2018, Vitalijs } \\
2017\end{array}$ & Russia & $\begin{array}{l}\text { descending } \\
\text { auction }\end{array}$ & all & $\begin{array}{l}\text { whole public } \\
\text { sector }\end{array}$ & all & no \\
\hline $\begin{array}{l}\text { Giuffrida \& Rovigatti } \\
\text { 2018, Decarolis et al. } \\
\text { 2018, Liebman \& Ma- } \\
\text { honey } 2017\end{array}$ & U.S. & several & all & federal & winning & no \\
\hline Gugler et al. 2015 & Austria & first price & construction & $\begin{array}{l}\text { federal and } \\
\text { regional }\end{array}$ & all & no \\
\hline $\begin{array}{l}\text { Coviello \& Gagliarducci } \\
2017\end{array}$ & Italy & $\begin{array}{l}\text { avg. bid } \\
\text { mechanism }\end{array}$ & all & municipal & winning & no \\
\hline Ferraz et al. 2016 & Brazil & $\begin{array}{l}\text { candle auc- } \\
\text { tion }\end{array}$ & all & federal & all & no \\
\hline $\begin{array}{l}\text { Baranek \& Titl 2018, } \\
\text { Palguta \& Pertold } 2017\end{array}$ & $\begin{array}{l}\text { Czech } \\
\text { Republic }\end{array}$ & first price & all & $\begin{array}{l}\text { national and } \\
\text { regional }\end{array}$ & winning & no \\
\hline Lee 2017, Schoenherr 2018 & Korea & $\begin{array}{l}\text { avg. bid } \\
\text { mechanism }\end{array}$ & all & government & all & no \\
\hline Straub 2018 & Paraguay & several & all & $\begin{array}{l}\text { whole public } \\
\text { sector }\end{array}$ & winning & no \\
\hline Lewis-Faupel et al. 2016 & $\begin{array}{l}\text { India, In- } \\
\text { donesia }\end{array}$ & several & construction & $\begin{array}{l}\text { states and } \\
\text { provinces }\end{array}$ & winning & no \\
\hline
\end{tabular}




\section{Competition}

The key practical concern in the public procurement regime in Finland and elsewhere is whether there will be enough bidders in public procurement contract awards. Attracting enough competition also seems to be the central ingredient from both an academic and an intuitive perspective in making public procurement auctions work in getting high-quality goods and services at reasonable prices (Bulow \& Klemperer 1996, Klemperer 2000). The first analysis in this section concerns the extent of competition in Finnish PP overall.

The second analysis in this section concerns how competition affects prices. The standard (auction theory) competition argument ("competition effect") predicts that an increase in competition, i.e. a higher number of actual bidders (denoted with $n$ ), leads to lower prices (and/or higher quality) in PP. This is because more aggressive bidding is needed to win with more intense competition. However, auction theory (and evidence) also argues that competition may sometimes have the opposite effect. In common-value PP auctions, the winner is the bidder who has estimated the production costs to be lowest (even if costs are the same for all bidders). Thus the winner may suffer from the winner's curse as the real production costs are higher than the winner thought. This underestimation becomes more severe as the number of bidders increases. Rational bidders account for this and bid less aggressively as competition increases. This is called the "Common values effect" (Bulow et al. 1999, Hong \& Shum 2002). A similar winner's curse may arise in affiliated values auctions where the bidder with the lowest signal on the costs (i.e. the winner) also believes that the other bidders have very low signals, and thus assumes that a lower bid is needed to win that they would assume without the updating of their beliefs resulting from affiliation. A rational bidder who accounts for this bids less conservatively the more competition there is. This is called the "Affiliation effect" (Pinkse \& Tan 2005, Hubbard et al. 2012). An "Entry effect" (Li \& Zheng 2009) means that the higher the number of potential bidders (denoted with $N$ ), the less profitable it is to enter due to the more intense competition, and thus it does not make sense to pay the entry costs. Thus an increase in $N$ may lead to a decrease in $n$. Due to these concerns, it is an empirical question whether competition has the desired effects. It may also be the case that the effects are nonlinear and the relationship may even reverse at some point. Moreover, the effects of competition are likely to vary case-by-case.

Estimating the effect of competition on prices is tricky, e.g. due to variables being omitted 
and the selection of bidders via entry. In the auction literature, this is typically addressed with structural models (or experimental designs in the lab). However, the scope of our paper is descriptive. We try to address these issues to some extent through measurement and by providing different types of analyses for which the methodological issues differ.

First, we use $\frac{\text { Runner-up bid-lowest bid }}{\text { Runner-up bid }}=$ Win margin (available for all auctions with $\mathrm{n}>1$ ) as one key measure. The second measure is Expected price ("engineer estimate") - Realized price $^{8}$. These scalings partially address the omitted variables issues (contract heterogeneity) by differencing across bidders within the same auction, but may involve some other issues such as the win margin and $n$ having a mechanical relationship. ${ }^{9}$ We correlate these measures with $n$ and $N$ (potential bidders). Using both $n$ and $N$ partially addresses the selection issue. However, e.g. collusion may still be an issue. For example, if bidders submit phony bids, then the observed $n$ is upward-biased from the real level of competition. $N$ and $n$ are also somewhat limited in information content if bidders are very asymmetric.

First, we analyze the extent of competition. In the left half of the Table 3 , we describe the data at the ITT level and report the share of ITTs that have a given number of distinct actual bidders (unique actual bidder identities across all the auctions within the ITT), distinct actual bidders conditional on there being at least one, and registrations for the ITT. In the right half of Table 3, we describe the data at the auction level. We report the shares of ITTs within a given bracket as the average number of bidders across the auctions within the ITT, both unconditionally and conditionally on there being at least one actual bidder. The difference between the ITT level and the auction level is potentially relevant as one ITT can contain many auctions in which different bidders participate.

As reported in Table 3, 31\% of ITTs have no actual bidders (first row of column 2). This is mainly due to the lack of entry of potential bidders as only $5.7 \%$ of ITTs have no potential bidders (first row of column 4). 15.6\% of tenders have only one actual bidder (row 2, column 2) and $14.2 \%$ only two (row 3, column 2). Less than $10 \%$ of ITTs have more than 6 bidders. A similar picture emerges when we look at the actual auction level within the ITTs, where the

\footnotetext{
${ }^{8}$ Expected price is available for about $75 \%$ of ITTs, whereas realized price is available only for about $3 \%$ of ITTs. The reason is that where bids are in unit prices we do not often observe the respective quantities of those units. Overall, this measure is thus available only for $3 \%$ of ITTs.

${ }^{9}$ The more draws are taken from a continuous distribution, the smaller the expected difference between the smallest and the second smallest value gets.
} 
Table 3: Shares of ITTs with a given number of actual or potential bidders

\begin{tabular}{llll||lll}
\hline \hline & & \multicolumn{2}{c||}{ ITT level } & \multicolumn{3}{c}{ Auction level } \\
count & bidders (n) & bidders $(\mathrm{n}>0)$ & registrations (N) & count bracket & bids & bids (n>0) \\
\hline 0 & $30.66 \%$ & & $5.64 \%$ & $0-0.99$ & $35.85 \%$ & $7.43 \%$ \\
1 & $15.50 \%$ & $22.37 \%$ & $9.43 \%$ & $1-1.99$ & $17.01 \%$ & $24.54 \%$ \\
2 & $14.27 \%$ & $20.56 \%$ & $9.26 \%$ & $2-2.99$ & $15.25 \%$ & $22.01 \%$ \\
3 & $11.31 \%$ & $16.30 \%$ & $10.71 \%$ & $3-3.99$ & $11.36 \%$ & $16.40 \%$ \\
4 & $8.17 \%$ & $11.79 \%$ & $10.18 \%$ & $4-4.99$ & $7.07 \%$ & $10.20 \%$ \\
5 & $5.28 \%$ & $7.62 \%$ & $8.95 \%$ & $5-5.99$ & $4.40 \%$ & $6.34 \%$ \\
6 & $3.70 \%$ & $5.34 \%$ & $7.47 \%$ & $6-6.99$ & $2.78 \%$ & $4.01 \%$ \\
7 & $2.37 \%$ & $3.42 \%$ & $6.26 \%$ & $7-7.99$ & $1.80 \%$ & $2.60 \%$ \\
8 & $1.81 \%$ & $2.61 \%$ & $5.23 \%$ & $8-8.99$ & $1.16 \%$ & $1.67 \%$ \\
9 & $1.35 \%$ & $1.94 \%$ & $4.20 \%$ & $9-9.99$ & $0.74 \%$ & $1.07 \%$ \\
$10+$ & $5.58 \%$ & $8.04 \%$ & $22.68 \%$ & $10-$ & $2.58 \%$ & $3.72 \%$ \\
\hline obs & 19467 & 13491 & 19467 & obs & 19467 & 13491 \\
\hline \hline
\end{tabular}

Notes: The left side of the table presents the shares of invitations to tender with the distinct number of actual bidders and registrations (potential bidders) respectively at the ITT level. Bidders are calculated as the number of distinct actual bidders in an ITT who have submitted at least one bid. The shares of ITTs are reported separately for ITTs with at least one bidder. The right half of the table presents the shares of ITTs at the auction level with average numbers of distinct bids per auction in an ITT. These bids are calculated first for each auction with the ITT, then averaged over the ITT, and then categorized into brackets. There are some ITTs where the average number of bids is lower than one even though the number of bidders is one or more, because there can be auctions where a bidder has not bid.

real competition takes place (rows 6 and 7 in Table 3 ).

Levels of competition seem to be low across all industries and procurers as shown in Table 4 . The median of distinct actual bidders per auction is only two across all industries. The median is also two across other procurers than government where it is only one. It is interesting that municipalities can attract on average (or median) at least as much competition, and often more, than any of the other (bigger) administrative units based on all the five competition measures in Table 4. This indirectly and tentatively implies that small rural municipalities may not be the key concern in terms of lack of competition, but perhaps rather overly large and cumbersome contracts. 
Table 4: Mean and median distinct bidders, avg. bids in auctions, registrations and win margin

\begin{tabular}{|c|c|c|c|c|c|c|c|}
\hline \multicolumn{2}{|l|}{ Panel A } & \multirow[b]{2}{*}{ bidders } & \multirow[b]{2}{*}{ bidders $\mathrm{n}>0$} & \multirow[b]{2}{*}{ bids } & \multirow[b]{2}{*}{ bids $n>0$} & \multirow[b]{2}{*}{ registrations } & \multirow[b]{2}{*}{ win margin } \\
\hline & & & & & & & \\
\hline \multirow[t]{3}{*}{ Construction } & mean & 3.32 & 5.21 & 2.73 & 4.28 & 7.89 & 0.32 \\
\hline & median & 2 & 4 & 2 & 3.81 & 6 & 0.15 \\
\hline & obs & 3,541 & 2,256 & 3,541 & 2,256 & 3,541 & 1,942 \\
\hline \multirow[t]{3}{*}{ Goods } & mean & 2.59 & 3.55 & 1.93 & 2.65 & 6.34 & 0.38 \\
\hline & median & 2 & 3 & 1.60 & 2 & 5 & 0.21 \\
\hline & obs & 6,413 & 4,665 & 6,413 & 4,665 & 6,413 & 3,542 \\
\hline \multirow[t]{3}{*}{ Services } & mean & 3.31 & 4.95 & 2.41 & 3.61 & 8.69 & 0.51 \\
\hline & median & 2 & 3 & 1.67 & 3 & 6 & 0.28 \\
\hline & obs & 4,955 & 3,305 & 4,955 & 3,305 & 4,955 & 2,714 \\
\hline \multirow[t]{3}{*}{ Social and health care } & mean & 5.61 & 8.07 & 3.34 & 4.81 & 11.32 & 0.41 \\
\hline & median & 2 & 3 & 1.40 & 2.50 & 6 & 0.17 \\
\hline & obs & 1,349 & 938 & 1,349 & 938 & 1,349 & 742 \\
\hline \multirow[t]{2}{*}{ Panel B } & & & & & & & \\
\hline & & bidders & bidders $\mathrm{n}>0$ & bids & bids $n>0$ & registrations & win margin \\
\hline \multirow[t]{3}{*}{ Government } & mean & 2.94 & 5.06 & 1.90 & 3.27 & 9.25 & 0.42 \\
\hline & median & 1 & 3 & 1 & 2 & 4 & 0.17 \\
\hline & obs & 2,021 & 1,175 & 2,021 & 1,175 & 2,021 & 824 \\
\hline \multirow[t]{3}{*}{ Health care districts } & mean & 2.59 & 3.85 & 1.85 & 2.76 & 5.94 & 0.39 \\
\hline & median & 2 & 3 & 1 & 2 & 4 & 0.21 \\
\hline & obs & 1,969 & 1,323 & 1,969 & 1,323 & 1,969 & 987 \\
\hline \multirow[t]{3}{*}{ Joint municipalities } & mean & 2.84 & 4.41 & 1.95 & 3.03 & 7.58 & 0.44 \\
\hline & median & 2 & 3 & 1.20 & 2.40 & 5 & 0.23 \\
\hline & obs & 2,133 & 1,374 & 2,133 & 1,374 & 2,133 & 1,124 \\
\hline \multirow[t]{3}{*}{ Municipalities } & mean & 3.21 & 4.44 & 2.43 & 3.37 & 7.35 & 0.42 \\
\hline & median & 2 & 3 & 1.93 & 2.66 & 5 & 0.21 \\
\hline & obs & 13,344 & 9,619 & 13,344 & 9,619 & 13,344 & 7,438 \\
\hline
\end{tabular}

Notes: Panel A presents statistics by industry and panel B presents them by procurer. Registrations (potential bidders) depict the number of distinct firms registered for an ITT. Bidders are calculated as the number of distinct actual bidders in an ITT who have submitted at least one bid. Bids and win margin are calculated first for each auction, then averaged for the ITT, and then for the industry. Bidder and bid statistics are also calculated for the whole sample as well as separately for ITTs with at least one bidder. The unit of observation is ITT.

Second, we analyze the correlation between our standardized price measures and the level of competition. The pattern of results shown in Figure 3 (see also Table 15 in the appendix) and Table 5 suggests that by and large competition is desirable for procurers as it decreases 
the win margin. However, the relationship between win margin and $n$ and $N$ is not monotonic. This is consistent with case studies (structural econometrics of single industries) showing nonmonotonicity due to the common values effect, the affiliation effect or the entry effect. Moreover, the relationship is nonlinear as the relationship flattens after about six actual bidders. This nonlinearity is further confirmed in Table 6, where the quadratic relationship between win margin and $n$ (bids) is very robust to adding various control variables and fixed effects. This implies that six actual bidders seem to be "enough" competition to achieve about as narrow win margins as feasible.

Table 7 shows that the difference between the expected and realized price also gets larger (expected prices are overestimated more) as the number of bidders increases, providing further support that higher levels of competition are desirable. Therefore, it seems that the vast majority of Finnish PP would benefit from more actual (and potential) bidders.

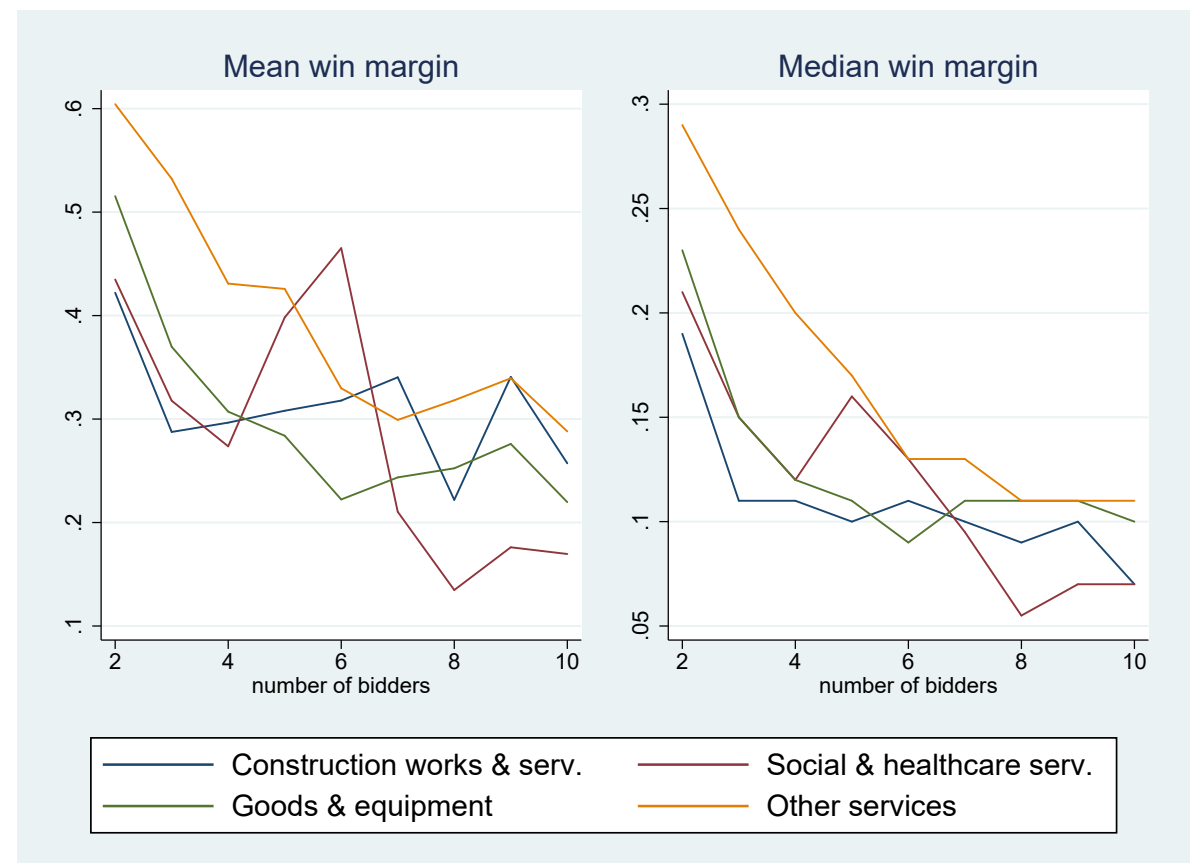

Figure 3: Mean and median win margins

Notes: Win margins are graphed as a function of the number of bidders. Graphs are presented by industry. Number of bidders is right-censored at 10 . 
Table 5: Win margin for number of bidders (n) and registrations (N)

\begin{tabular}{|c|c|c|c|c|c|c|}
\hline \multirow[t]{2}{*}{ count } & \multicolumn{3}{|c|}{ win margin by $n$} & \multicolumn{3}{|c|}{ win margin by $\mathrm{N}$} \\
\hline & obs & mean & median & obs & mean & median \\
\hline 2 & 33,936 & $\begin{array}{l}0.84 \\
(3.34)\end{array}$ & 0.25 & 3,766 & $\begin{array}{l}0.74 \\
(2.89)\end{array}$ & 0.20 \\
\hline 3 & 32,937 & $\begin{array}{l}0.55 \\
(2.11)\end{array}$ & 0.17 & 6,613 & $\begin{array}{l}0.53 \\
(1.87)\end{array}$ & 0.18 \\
\hline 4 & 22,510 & $\begin{array}{l}0.50 \\
(2.90)\end{array}$ & 0.13 & 8,753 & $\begin{array}{l}0.66 \\
(3.05)\end{array}$ & 0.15 \\
\hline 5 & 14,530 & $\begin{array}{l}0.51 \\
(2.72)\end{array}$ & 0.12 & 9,847 & $\begin{array}{l}0.48 \\
(1.44)\end{array}$ & 0.18 \\
\hline 6 & 8,698 & $\begin{array}{l}0.29 \\
(1.17)\end{array}$ & 0.09 & 10,676 & $\begin{array}{l}0.52 \\
(1.74)\end{array}$ & 0.18 \\
\hline 7 & 5,528 & $\begin{array}{l}0.30 \\
(1.60)\end{array}$ & 0.10 & 9,659 & $\begin{array}{l}0.51 \\
(2.20)\end{array}$ & 0.16 \\
\hline 8 & 3,569 & $\begin{array}{l}0.34 \\
(1.65)\end{array}$ & 0.10 & 12,666 & $\begin{array}{l}0.49 \\
(2.16)\end{array}$ & 0.12 \\
\hline 9 & 2,575 & $\begin{array}{l}0.33 \\
(1.60)\end{array}$ & 0.09 & 8,050 & $\begin{array}{l}0.57 \\
(2.58)\end{array}$ & 0.16 \\
\hline $10+$ & 9,443 & $\begin{array}{l}0.30 \\
(1.69)\end{array}$ & 0.07 & 61,041 & $\begin{array}{l}0.53 \\
(2.71)\end{array}$ & 0.14 \\
\hline
\end{tabular}

Notes: Win margin is calculated as the percentage difference between the lowest and the second lowest bid. Number of registered firms in an auction is extrapolated using the number of registered bidders in an ITT. Standard deviation reported in parenthesis below mean. The unit of observation is auction. 
Table 6: Quantile regressions on win margin

\begin{tabular}{|c|c|c|c|c|}
\hline & $(1)$ & $(2)$ & $(3)$ & $(4)$ \\
\hline \multirow[t]{2}{*}{ Bids } & $-0.0120^{* * *}$ & $-0.0104^{* * *}$ & $-0.0123^{* * *}$ & $-0.0124^{* * *}$ \\
\hline & $(0.000285)$ & $(0.000335)$ & $(0.000402)$ & $(0.000403)$ \\
\hline \multirow[t]{2}{*}{$\operatorname{Bids}^{2}$} & $0.000156^{* * *}$ & $0.0000778^{* * *}$ & $0.0000887^{* * *}$ & $0.0000889^{* * *}$ \\
\hline & $(0.00000266)$ & $(0.00000283)$ & $(0.00000322)$ & $(0.00000322)$ \\
\hline \multirow[t]{2}{*}{ Scoring } & & 0 & $-0.00588^{* *}$ & $-0.00787^{* * *}$ \\
\hline & & $(0.00177)$ & $(0.00213)$ & $(0.00229)$ \\
\hline \multirow[t]{2}{*}{ Partial bids allowed } & & $-0.0192^{* * *}$ & 0.000900 & -0.00127 \\
\hline & & $(0.00175)$ & $(0.00223)$ & $(0.00226)$ \\
\hline \multirow[t]{2}{*}{ Healthcare district } & & & & -0.0102 \\
\hline & & & & $(0.00735)$ \\
\hline \multirow[t]{2}{*}{ Joint municipalities } & & & & -0.00118 \\
\hline & & & & $(0.00683)$ \\
\hline \multirow[t]{2}{*}{ Municipalities } & & & & $0.0138^{*}$ \\
\hline & & & & $(0.00624)$ \\
\hline \multirow[t]{2}{*}{ Constant } & $0.205^{* * *}$ & $0.210^{* * *}$ & $0.146^{* * *}$ & $0.136^{* * *}$ \\
\hline & $(0.00139)$ & $(0.00196)$ & $(0.00709)$ & $(0.0130)$ \\
\hline Observations & 138588 & 114240 & 110050 & 110050 \\
\hline Industry FE & No & No & Yes & Yes \\
\hline Month FE & No & No & No & Yes \\
\hline Year FE & No & No & No & Yes \\
\hline
\end{tabular}

Standard errors in parentheses. ${ }^{*} p<0.05,{ }^{* *} p<0.01,{ }^{* * *} p<0.001$

Notes: Quantile regression is used to combat excessive outliers in the data. 2-digit CPV classification is used for industry fixed effects. Government is used as the baseline procurer. Standard errors clustered at industry level. The unit of observation is auction. 
Table 7: Mean and median percentage difference in estimated and realized costs

\begin{tabular}{|c|c|c|c|c|c|c|}
\hline \multirow[b]{2}{*}{ bids } & \multicolumn{3}{|c|}{ Cost difference by bids } & \multicolumn{3}{|c|}{ Cost difference by registrations } \\
\hline & obs & mean & median & obs & mean & median \\
\hline 1 & 153 & $\begin{array}{l}0.24 \\
(0.21) \\
\end{array}$ & 0.18 & 82 & $\begin{array}{l}0.22 \\
(0.18) \\
\end{array}$ & 0.20 \\
\hline 2 & 134 & $\begin{array}{l}0.29 \\
(0.24)\end{array}$ & 0.22 & 85 & $\begin{array}{l}0.28 \\
(0.22)\end{array}$ & 0.23 \\
\hline 3 & 69 & $\begin{array}{l}0.34 \\
(0.24) \\
\end{array}$ & 0.27 & 83 & $\begin{array}{l}0.28 \\
(0.24)\end{array}$ & 0.20 \\
\hline 4 & 37 & $\begin{array}{l}0.36 \\
(0.29)\end{array}$ & 0.34 & 54 & $\begin{array}{l}0.25 \\
(0.23)\end{array}$ & 0.17 \\
\hline $5+$ & 50 & $\begin{array}{l}0.48 \\
(0.27)\end{array}$ & 0.51 & 139 & $\begin{array}{l}0.41 \\
(0.28)\end{array}$ & 0.36 \\
\hline
\end{tabular}

Notes: Differences are presented only for procurement in the goods category where the quantities procured are known. Realized cost is calculated using data on bids and the amounts procured. Due to scarcity in data the sample size is small. Standard deviations are reported in parentheses below the mean. The unit of observation is ITT. 


\section{$4 \quad$ Entry}

In this section, we turn to analyzing entry decisions. The main goal is to analyze why the levels of competition are so low. What are the possible obstacles to attracting more potential bidders and getting potential bidders to actually bid? The key policy design questions are whether more competition can be attracted by means of contract design or by decreasing entry costs.

We analyze entry by looking at how $n$ and $N$ relate to each other. In particular, we analyze $n / N$. This measures the share of actual bidders among the potential bidders. We correlate this measure with $n$. We also study whether this correlation varies across industries or whether we can predict it in other ways. Theoretically, the analysis will also potentially help to understand whether entry should be seriously accounted for when modeling PP and designing policy.

First, in Table 8, we give the means and medians of the potential and actual bidders at the ITT level, as well as actual bids per auction within an ITT conditional on whether the auction mechanism is scoring or not, and partial or not. Both of these are design features that the procurer could feasibly adjust in many cases. The use of a scoring auction is correlated with slightly less competition based on all measures, but the differences are small. For the partial or not comparison, the relevant measure is actual bids per auction in the middle column as the other measures differ due to mechanical reason that in partial ITTs there are always more auctions. Partial ITTs attract slightly more bids per auction on average, but nonetheless have higher win margins. While both these correlations are suggestive of auction rules possibly influencing the amount of competition, we should not base policy implications on such simple correlations.

Second, in Table 9 we analyze entry patterns by regressing $n$ (at both the ITT and auction level), $N$ and $n / N$ on the ITT characteristics of using scoring and partial mechanisms, and ITT size in estimated value while controlling for industry, region and year fixed effects. The observed auction characteristics seem not to be very successful overall in predicting competition and entry. Partial mechanism is a significant predictor only for the ITT level $n$ and $N$, but that is likely just mechanical, whereas it is not significant at its relevant column of auction level $n$. Scoring is not a statistically significant predictor of any outcome. ITT size shows some interesting patterns. Larger contracts have more potential bidders, but they bid less often as ITT size negatively predicts $n / N$. The resulting actual number of bidders remains roughly unaffected. However, the size effects are fairly small in magnitude as the unit is in million 
Table 8: Differences in competition for ITTs with and without scoring rule and ITTs with and without partial procurement

\begin{tabular}{lc|cc|cc|cc}
\hline \hline \multirow{2}{*}{ No scoring } & mean & 3.33 & 4.72 & 2.49 & 3.53 & 7.93 & 0.40 \\
& median & 2 & 3 & 2 & 3 & 6 & 0.21 \\
& obs & 9,269 & 6,543 & 9,269 & 6,543 & 9,269 & 5,295 \\
\hline Scoring & mean & 2.88 & 4.40 & 2.09 & 3.21 & 7.14 & 0.41 \\
& median & 2 & 3 & 1 & 2.18 & 5 & 0.21 \\
& obs & 7,170 & 4,679 & 7,170 & 4,679 & 7,170 & 3,599 \\
\hline \hline No partial & mean & 2.27 & 3.34 & 2.13 & 3.14 & 5.66 & 0.42 \\
& median & 2 & 3 & 1 & 2 & 4 & 0.20 \\
\hline \multirow{2}{*}{ Partial } & obs & 14,356 & 9,738 & 14,356 & 9,738 & 14,356 & 7,316 \\
\hline \hline & mean & 5.35 & 7.28 & 2.64 & 3.60 & 12.40 & 0.43 \\
& median & 3 & 4 & 1.71 & 2.57 & 8 & 0.24 \\
\hline
\end{tabular}

Notes: Scoring refers to ITTs which were awarded using a scoring rule. Partial refers to ITTs that were split into smaller, separately awarded contracts. Bids and win margins are calculated first for each auction, then averaged for the ITT. Bidder and bid statistics are also calculated and presented separately for ITTs with at least one bidder. The unit of observation is ITT.

euro and typically the contracts are much smaller (median estimated value is 0.157 million euro), implying that adjusting size is of limited practical relevance for affecting competition. Overall, these results suggest that the contract or auction design can be of only limited help in increasing competition. However, we look at a fairly limited set of contract characteristics as we have no information on e.g. quality requirements. Moreover, this analysis does not yet account for bidder characteristics. Nonetheless, a more fruitful avenue may be to alleviate the issues related to the lack of competition rather than trying to affect competition levels directly. Reservation prices offer a standard solution to limiting the adverse price effects resulting from a lack of competition.

In Figure 4, we report 95\% confidence intervals for the mean and median of $n / N$ for each $n$. In the information acquisition model of Levin \& Smith (1994), bidders have to pay an entry cost to acquire information about their production costs. This results in mixed strategy equilibrium, where the entry probabilities decrease as $N$ increases. This is because entry is profitable in expectation only for a limited number of actual bidders and this number is independent of $N$, 
Table 9: OLS regressions on number of registered firms (N), number of bidders $(\mathrm{n})$ and share of bidders to registered firms $(\mathrm{n} / \mathrm{N})$

\begin{tabular}{|c|c|c|c|c|c|c|c|}
\hline \multirow[t]{2}{*}{ Dependent variable } & \multicolumn{2}{|c|}{$\mathrm{N}$} & \multicolumn{2}{|c|}{$\mathrm{n}(\mathrm{ITT})$} & \multirow{2}{*}{$\begin{array}{c}\mathrm{n} \text { (auction) } \\
(5)\end{array}$} & \multicolumn{2}{|c|}{$\mathrm{n} / \mathrm{N}$} \\
\hline & (1) & $(2)$ & (3) & (4) & & (6) & (7) \\
\hline \multirow[t]{2}{*}{ Scoring } & 0.701 & 0.554 & -0.213 & -0.182 & -0.2226 & -0.00267 & -0.00398 \\
\hline & $(0.416)$ & $(0.391)$ & $(0.275)$ & $(0.275)$ & $(0.1442)$ & $(0.00883)$ & $(0.00955)$ \\
\hline \multirow[t]{2}{*}{ Partial bids allowed } & $6.429^{* * *}$ & $5.854^{* * *}$ & $2.890^{* * *}$ & $2.830^{* * *}$ & 0.272 & -0.0219 & -0.0154 \\
\hline & $(0.970)$ & $(0.931)$ & $(0.560)$ & $(0.582)$ & $(0.150)$ & $(0.0202)$ & $(0.0202)$ \\
\hline \multirow[t]{2}{*}{ Estimated value } & & $0.730^{*}$ & & 0.125 & & & $-0.00253^{*}$ \\
\hline & & $(0.340)$ & & $(0.118)$ & & & $(0.00124)$ \\
\hline \multirow[t]{2}{*}{ Estimated value $^{2}$} & & -0.00154 & & -0.0000153 & & & $-0.00000774^{*}$ \\
\hline & & $(0.000852)$ & & $(0.000266)$ & & & $(0.00000327)$ \\
\hline \multirow[t]{2}{*}{ Constant } & $10.97^{* *}$ & $6.283^{* * *}$ & $3.115^{* *}$ & $1.580^{*}$ & 4.789 & $0.440^{* * *}$ & $0.475^{* * *}$ \\
\hline & $(3.485)$ & $(1.212)$ & $(1.140)$ & $(0.596)$ & $(1.324)$ & $(0.0264)$ & $(0.0326)$ \\
\hline Observations & 13708 & 11750 & 13708 & 11750 & 86591 & 10157 & 8798 \\
\hline$R^{2}$ & 0.20 & 0.27 & 0.10 & 0.12 & 0.11 & 0.08 & 0.09 \\
\hline Industry FE & Yes & Yes & Yes & Yes & Yes & Yes & Yes \\
\hline Area FE & Yes & Yes & Yes & Yes & Yes & Yes & Yes \\
\hline Year FE & Yes & Yes & Yes & Yes & Yes & Yes & Yes \\
\hline
\end{tabular}

Standard errors in parentheses. ${ }^{*} p<0.05,{ }^{* *} p<0.01,{ }^{* * *} p<0.001$

Notes: Regressions were run on the number of bidders (n) for the ITT and auction level respectively. 2-digit CPV classification is used for industry fixed effects. Municipalities are used for area fixed effects. For joint municipalities and health care districts, region is used instead. Estimated value is available for $70 \%$ of ITTs. Estimated value is in million euro. Standard errors are clustered at the industry level. The unit of observation is ITT except for regression (5) where the unit is auction.

and rather depends on the entry costs and expected profits (that depend on $n$ ). Therefore, $n$ is independent of $N$, and thus $n / N$ increases in $n$. Moreover, the relation increases more steeply for smaller compared to large values of $n$. This is exactly what we see in Figure 4. The mixed strategy equilibrium also implies that some or even fairly many auctions may have zero or only one bidder, even if there would have been more potential entrants for whom it would have been ex-post profitable to enter. This is also consistent with our data even though this is indirect evidence as we do not observe profitability.

In contrast, the bid preparation costs model of Samuelson (1985) is less consistent with the evidence. In this model, bidders know their production costs, but have to pay a bid preparation cost or entry fee to enter. All bidders with production costs below a certain threshold enter. The threshold depends on the entry costs and expected profits (which depend on $n$ ). As $N$ increases, more bidders have valuations below the threshold, and thus $n$ increases. This means that unlike in the Levin \& Smith (1994) model, $n$ is not independent of $N$, but rather they 
are positively correlated. This would lead to a relatively constant relationship between $n / N$ in $n$. However, in this situation, the entry threshold in production costs may be adjusted with $N$ if $N$ is common knowledge, because that may influence the expected profits of entry via $n$. This mechanism could possibly also lead to an increasing $n / N$ in $n$, and thus, makes it complicated to infer the entry paradigm based solely on the relationship between $n / N$ in $n$. However, the key difference with an information acquisition model is that here entry is selective as only bidders with the lowest costs enter. This implies that bidder characteristics should be predictive in the margin where potential bidders decide to submit a bid. We study this below in reduced form. A more rigorous structural test of the entry paradigm using this idea is provided by Marmer et al. (2013), but implementing that is beyond the descriptive scope of our paper and is more suitable to case studies.

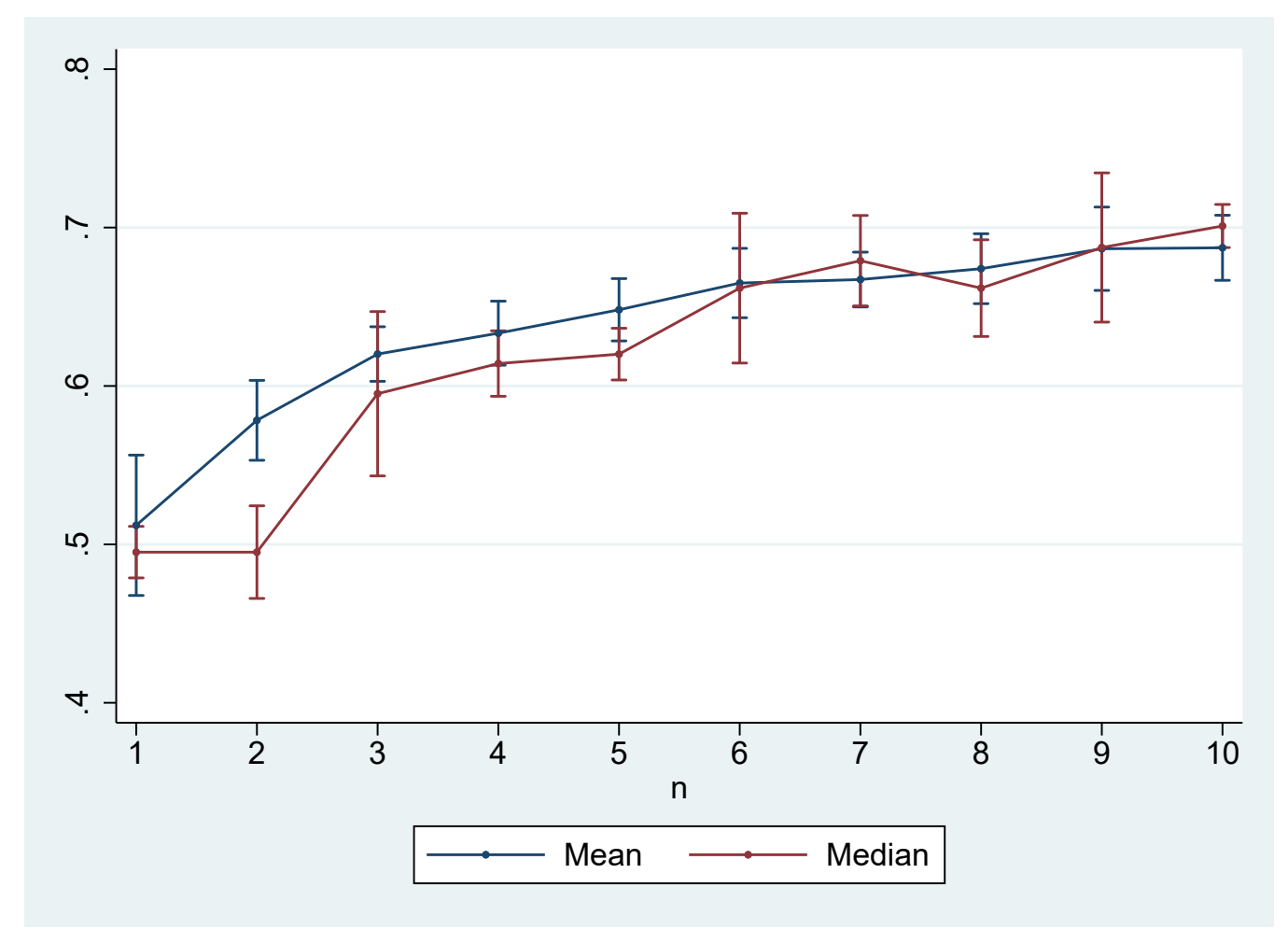

Figure 4: $95 \%$ confidence intervals of mean and median $\mathrm{n} / \mathrm{N}$ by $\mathrm{n}$

Notes: Means and medians are obtained by regressing $\mathrm{n} / \mathrm{N}$ on dummies for different $\mathrm{n}$. We control for industry, municipality and time fixed effects as well as the procurement method. Standard errors are clustered at the 2-digit CPV category level.

This analysis can also be informative for understanding what assumptions we should make about the theoretical relationship $n=f(N)$, when $N$ is unobserved. This is important for informing theoretical models and conducting structural auction econometrics, because the equilibrium behavior that identifies those models is typically based on the often unobserved $N$ 
(rather than the often observed $n$ ), or the expectation of $N$. In structural models, the researcher needs to assume the relationship $N=g(n)$, i.e. how to use the observed information to impute the unobserved. Typical practical solutions include assuming $N=n, N=\max \left(n_{i}\right)$, where $i$ denotes an auction and the researcher observes many auctions with the same set of potential bidders, $N$ equals the sum of unique bidder identities across a range of similar auctions, or $N=n+e$, where $e$ is random. We also study whether the relationship between $n$ and $N$ varies across industries?

Entry is an important feature as there are systematically many more potential than actual bidders in our data. The relationship between $n / N$ and $n$ seems to vary somewhat across industries (Figure 5). While the patterns in the data are not detailed enough to warrant strong conclusions, they are the least at odds with the practical assumption that $N$ equals the sum of unique bidders identities across a range of similar observed auctions. This is because the increasing relationship between $n / N$ and $n$, and the rough consistency of the data with the information acquisition model with mixed strategy entry, implies that for a fixed $N$ across many auctions, one would observe varying $n$ with different identities of actual bidders across the auctions.

We also analyze whether bidder characteristics can predict entry at various stages. Here we first identify for each auction the most common 3-digit industry code among the potential bidders. We use this to pick from the FLEED data (see Section 2) all the firms that have that code as their main industry. We treat this sample as all the firms that are relevant (could have registered but did not necessarily register) for the given ITT. Thus, for each auction, we can describe the characteristics of all the relevant firms, potential bidders, actual bidders and the winners. In Table 10, we report the median turnover, number of employees and profit margin of the unregistered (but relevant) firms, potential (registered) bidders, actual bidders and the winners. In Table 11, we present the share of firms in these four categories that are registered for business in the location of the contract either at the municipality or the province level.

Based on Tables 10 and 11, most selection seems to take place at the registering stage rather than at the entry (into bidding) stage when it comes to firm size and profitability, which is also more in line with the information acquisition model than the entry fee model. However, the locality of the firm correlates with the selection at both the registering and bidding stages, and also with winning (other than in the social and health care sector). This pattern can be rationalized by local firms having both lower information acquisition and production costs. 


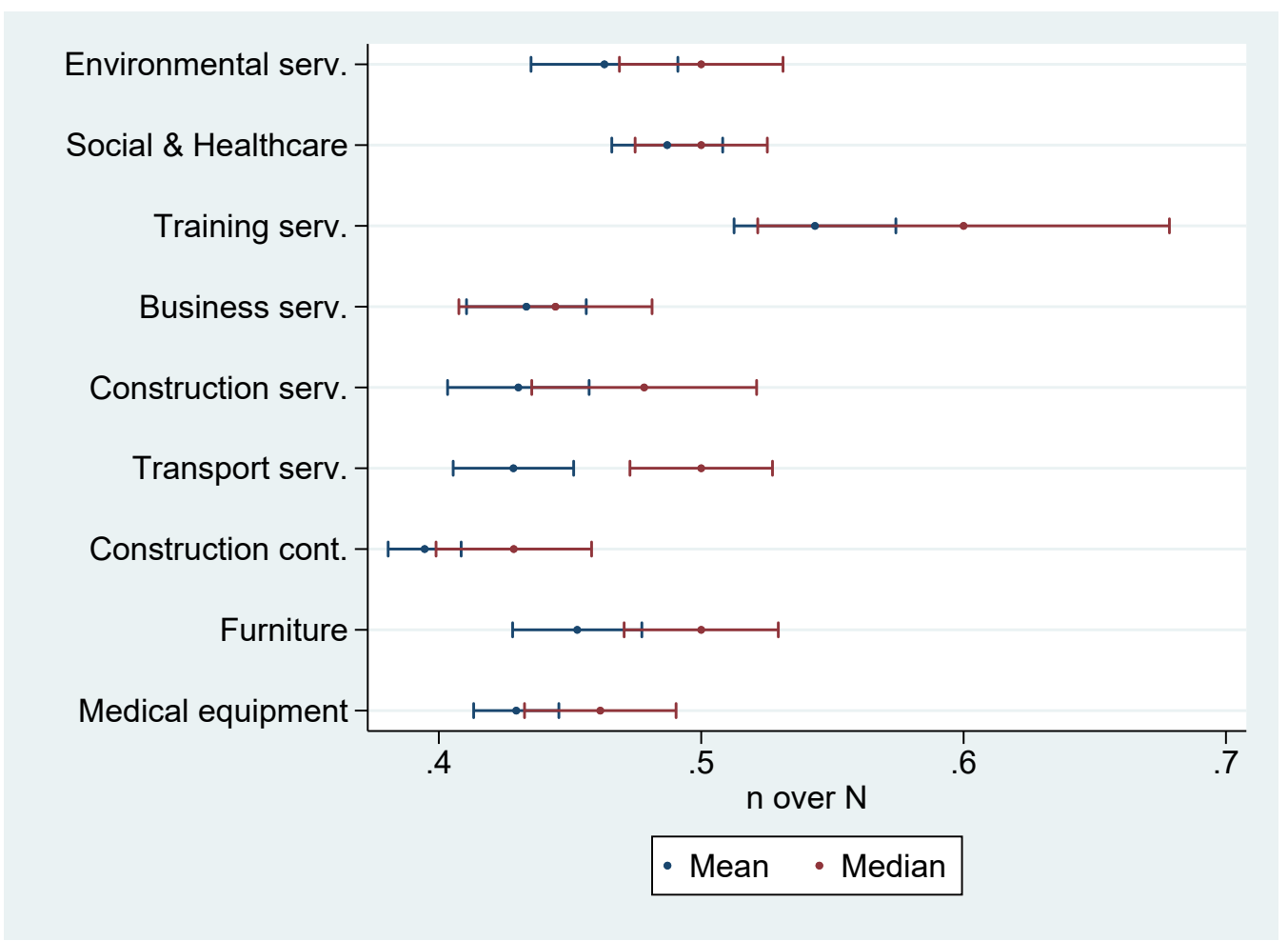

Figure 5: $95 \%$ confidence intervals of mean and median $\mathrm{n} / \mathrm{N}$ by industry

Notes: Means and medians are obtained by regressing $\mathrm{n} / \mathrm{N}$ on industry dummies. We control for municipality and time fixed effects as well as the procurement method. Standard errors are clustered at the 2-digit CPV category level.

However, it seems unlikely that bid preparation costs (entry fees) vary based on locality.

Based on Table 12, the results are similar when the firm characteristics are analyzed simultaneously in the entry decision (bidding conditional on registering) regression. Locality correlates strongly with entry. Previous experience in bidding is also a strong predictor. Other firm characteristics have less predictive power. Another interesting result is that the use of scoring auctions seems to correlate with less entry (as long as fixed effects are included). This indicates that careful consideration between minimum quality requirements (or other tools such as sanctions) and scoring as alternative ways to attract quality could be in order. 
Table 10: Median bidder turnover, employees and profit margin by industry

\begin{tabular}{lccccc}
\hline \hline \multirow{2}{*}{ Construction } & median & unregistered & registered & bid & won \\
& turnover & 446 & 5,012 & 6,682 & 10,278 \\
& employees & 2.00 & 16.79 & 21.16 & 30.00 \\
& profit margin & 0.03 & 0.02 & 0.02 & 0.02 \\
\hline \multirow{2}{*}{ Goods } & turnover & 200 & 938 & 1,605 & 1,039 \\
& employees & 1.96 & 7.73 & 14.40 & 9.10 \\
& profit margin & 0.09 & 0.04 & 0.03 & 0.04 \\
\hline \multirow{2}{*}{ Social and healthcare } & turnover & 214 & 1,829 & 1,093 & 1,562 \\
& employees & 1.38 & 18.40 & 12.10 & 17.00 \\
& profit margin & 0.15 & 0.03 & 0.03 & 0.03 \\
\hline \multirow{2}{*}{ Other services } & turnover & 257 & 2,136 & 3,950 & 3,069 \\
& employees & 2.08 & 12.37 & 21.87 & 19.12 \\
& profit margin & 0.06 & 0.03 & 0.02 & 0.02 \\
\hline \hline
\end{tabular}

Notes: Median bidder turnover (in thousands of euro), employees and profit margin are presented for unregistered, registered, bidding and winning firms. Columns are mutually exclusive at the ITT level, meaning that a firm can only belong to one column for each ITT it has participated in. For partial tenders, a firm that has won is counted only in the "won" column while a firm that has bid but hasn't won is counted in the "bid" column. Observations are at the ITT level. Unregistered firms are gathered from the Statistics Finland database and matched to the respective ITTs using industry classifications. Firms with turnover below 100000 euro are excluded from the unregistered firm pool. Observations are at the ITT level.

Table 11: Bidders' presence in procurer's municipality and province

\begin{tabular}{lccccc}
\hline \hline & presence in & unregistered & registered & bid & won \\
\hline Construction & municipality & 0.02 & 0.13 & 0.18 & 0.21 \\
& province & 0.10 & 0.26 & 0.34 & 0.37 \\
\hline Goods & municipality & 0.03 & 0.20 & 0.31 & 0.35 \\
& province & 0.12 & 0.40 & 0.52 & 0.55 \\
\hline \multirow{2}{*}{ Social and healthcare } & municipality & 0.03 & 0.24 & 0.36 & 0.22 \\
& province & 0.13 & 0.47 & 0.60 & 0.48 \\
\hline Other services & municipality & 0.02 & 0.23 & 0.30 & 0.40 \\
& province & 0.12 & 0.53 & 0.62 & 0.69 \\
\hline \hline
\end{tabular}

Notes: Share of firms present in procurer's municipality and province for unregistered, registered, bidding and winning firms. Columns are mutually exclusive at the ITT level, meaning that a firm can only belong to one column for each ITT it has participated in. A firm that has won is counted only in the "won" column while a firm that has bid but hasn't won is counted in the "bid" column. For joint municipalities a bidder is counted as present in a municipality if it is present in any of the procurers' municipalities. For health care districts bidders' presence is counted only at the province level. Unregistered firms are gathered from a Statistics Finland database and matched to respective ITTs using industry classifications. Firms with turnover below 100000 euro are excluded from the unregistered firm pool. Observations are at the ITT level. 
Table 12: Logit and LPM regressions on bidding conditional on registration

\begin{tabular}{|c|c|c|c|c|}
\hline \multirow[b]{2}{*}{ Dep. var.: Bid conditional on registration } & \multicolumn{2}{|c|}{ Logit } & \multicolumn{2}{|c|}{ LPM } \\
\hline & $(1)$ & $(2)$ & $(3)$ & $(4)$ \\
\hline \multirow[t]{2}{*}{ Bid in previous year } & $0.851^{* * *}$ & $0.739^{* * *}$ & $0.191^{* * *}$ & $0.159^{* * *}$ \\
\hline & $(0.0698)$ & $(0.0505)$ & $(0.0113)$ & $(0.00851)$ \\
\hline \multirow[t]{2}{*}{ Bid in previous year (same region and industry) } & $0.234^{* * *}$ & $0.255^{* * *}$ & $0.0578^{* * *}$ & $0.0611^{* * *}$ \\
\hline & $(0.0379)$ & $(0.0421)$ & $(0.00963)$ & $(0.0100)$ \\
\hline \multirow[t]{2}{*}{ Registered in previous year } & $-0.824^{* * *}$ & $-0.720^{* * *}$ & $-0.184^{* * *}$ & $-0.154^{* * *}$ \\
\hline & $(0.0828)$ & $(0.0606)$ & $(0.0208)$ & $(0.0138)$ \\
\hline \multirow[t]{2}{*}{ Present in same municipality } & $0.254^{* * *}$ & $0.256^{* * *}$ & $0.0615^{* * *}$ & $0.0603^{* * *}$ \\
\hline & $(0.0406)$ & $(0.0420)$ & $(0.00988)$ & $(0.00966)$ \\
\hline \multirow[t]{2}{*}{ Present in same province } & $0.180^{* *}$ & $0.187^{* * *}$ & $0.0430^{* *}$ & $0.0443^{* * *}$ \\
\hline & $(0.0559)$ & $(0.0486)$ & $(0.0135)$ & $(0.0112)$ \\
\hline \multirow[t]{2}{*}{ Backlog } & 0.0000197 & 0.0000159 & 0.00000451 & 0.00000417 \\
\hline & 0.0000182 & 0.0000151 & 0.00000439 & 0.00000371 \\
\hline \multirow[t]{2}{*}{ Backlog/Turnover } & $-0.0000403^{* *}$ & -0.0000144 & $-0.00000931^{* *}$ & -0.00000378 \\
\hline & $(0.0000139)$ & $(0.0000149)$ & $(0.00000300)$ & $(0.00000345)$ \\
\hline \multirow[t]{2}{*}{ Turnover } & 0.000112 & 0.000131 & 0.0000269 & 0.0000286 \\
\hline & $(0.000197)$ & $(0.000262)$ & $(0.0000422 \mathrm{e})$ & $(0.0000541)$ \\
\hline \multirow[t]{2}{*}{ Turnover $^{2}$} & -0.000000874 & -0.00000104 & -0.000000199 & -0.000000222 \\
\hline & $(0.000000997)$ & $(0.00000118)$ & $(0.000000183)$ & $(0.000000210)$ \\
\hline \multirow[t]{2}{*}{ Tender value/Turnover } & 0.00000349 & 0.00000662 & $-0.000000552^{* * *}$ & -0.000000362 \\
\hline & $(0.0000118)$ & $(0.00000961)$ & $(0.00000538)$ & $(0.000000209)$ \\
\hline \multirow[t]{2}{*}{$\left(^{\text {Tender value/Turnover })^{2}}\right.$} & -0.0000000000071 & -0.00000000000941 & $-0.000000000000152^{* * *}$ & -0.0000000000000706 \\
\hline & $(0.0000000000107)$ & $(0.00000000000887)$ & $(0.0000000000000299)$ & $(0.000000000000114)$ \\
\hline \multirow[t]{2}{*}{ Employees } & 0.00398 & 0.00421 & 0.000940 & 0.000979 \\
\hline & $(0.00211)$ & $(0.00263)$ & $(0.000484)$ & $(0.000581)$ \\
\hline \multirow[t]{2}{*}{ Scoring } & -0.173 & $-0.287^{* *}$ & -0.0409 & $-0.0655^{* *}$ \\
\hline & $(0.0957)$ & $(0.0931)$ & $(0.0228)$ & $(0.0206)$ \\
\hline \multirow[t]{2}{*}{ Partial } & 0.222 & 0.171 & $0.0512^{*}$ & 0.0387 \\
\hline & $(0.118)$ & $(0.102)$ & $(0.0243)$ & $(0.0215)$ \\
\hline \multirow[t]{2}{*}{ Tender value } & -0.0219 & -0.0185 & -0.00373 & -0.00296 \\
\hline & $(0.0273)$ & $(0.0266)$ & $(0.00221)$ & $(0.00186)$ \\
\hline \multirow[t]{2}{*}{ Tender value ${ }^{2}$} & 0.000112 & 0.0000875 & $0.00001211^{*}$ & $0.0000101^{*}$ \\
\hline & $(0.000328)$ & $(0.0000290)$ & $(0.00000561)$ & $(0.00000467)$ \\
\hline \multirow[t]{2}{*}{ Constant } & -0.232 & 0.142 & $0.441^{* * *}$ & $0.528^{* * *}$ \\
\hline & $(0.143)$ & $(0.243)$ & $(0.0335)$ & $(0.0529)$ \\
\hline Observations & 67517 & 67457 & 67517 & 67470 \\
\hline Industry FE & No & Yes & No & Yes \\
\hline Region FE & No & Yes & No & Yes \\
\hline Year FE & No & Yes & No & Yes \\
\hline
\end{tabular}

Standard errors in parentheses. ${ }^{*} p<0.05,{ }^{* *} p<0.01,{ }^{* * *} p<0.001$

Notes: Specifications (1) - (2) use a logit and (3) - (4) use a linear probability model. Dependent variable is a dummy indicating whether a firm has bid in any auction in an ITT conditional on registering for the given ITT. Backlog, turnover and tender values are in million euro. Employees are in 100s. Backlog is calculated taking the sum of the values of tenders awarded to the firm in our data during one year prior to the observed ITT. Standard errors are clustered at the industry level. Observations are registered firm - ITT pairs. 


\section{$5 \quad$ Bidder asymmetry}

Large asymmetries in productions costs between bidders also lead to less intense competition. Large asymmetries can work both as entry barriers (extensive margin) and also lead to less intense competition between the actual bidders (intensive margin).

In this section, we study to what extent bidders differ from each other in general and within auctions based on their observed characteristics. Of course, production costs are not observed. In Figure 6, we report the distribution of bidders by employee count to understand the overall heterogeneity in size. In Figure 7, we report the bidder distribution over within-ITT heterogeneity, measured as the maximum firm size divided by the mean firm size in employees within-ITT. We find that in general there is large heterogeneity in size between bidders, also within each auction. This should be accounted for when modeling public procurement auctions and conducting empirical analysis with public procurement data.

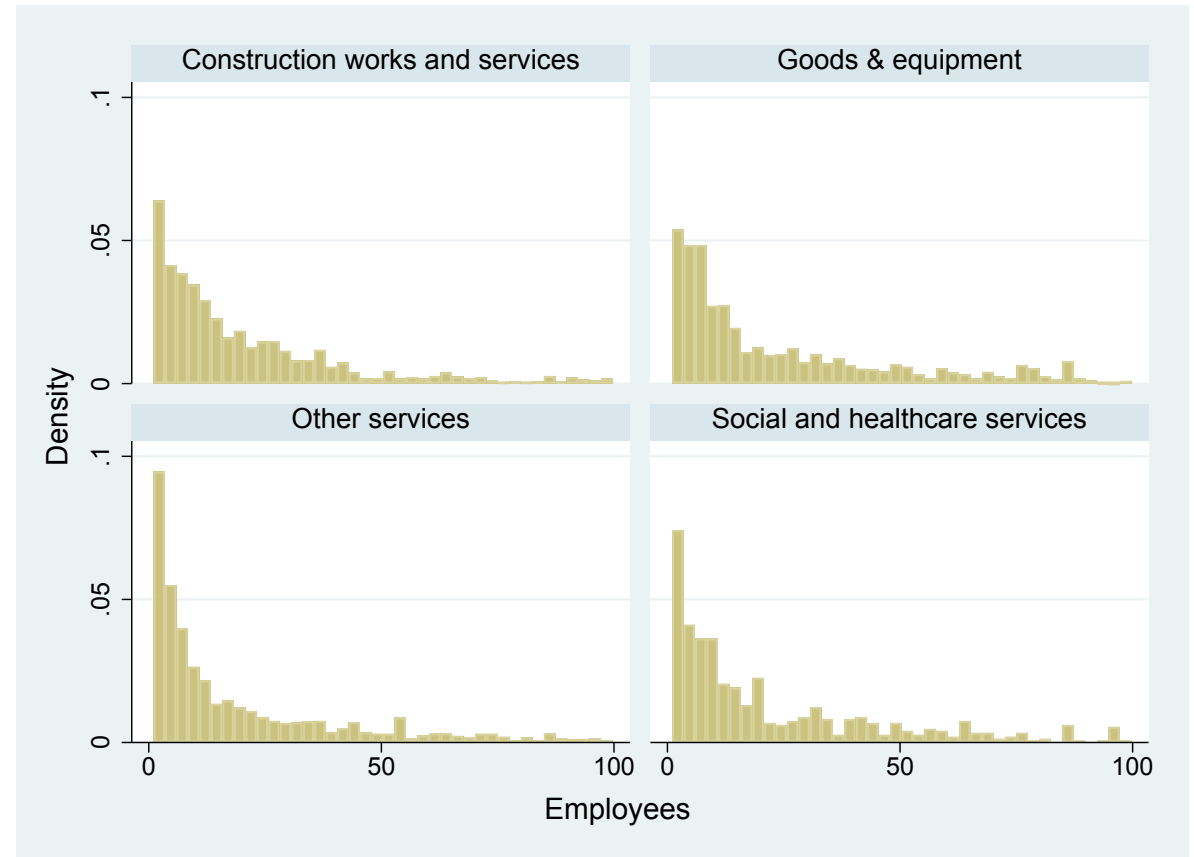

Figure 6: Distribution of bidders' employee count, by industry.

Notes: Bidders' employee counts are recorded as an average over the year the ITT took place. The unit of observation is bidder - ITT pair.

For the entry patterns, we saw that many small firms do not even register for auctions, and the analysis in this section shows that substantial asymmetries remain even after that selection. This suggests that perhaps the contract design should be tailored to attract more small firms. Also auction rules that favour smaller firms could intensify competition enough to offset the resulting inefficiencies. It also seems, based on Figure 8, that in general individual tenders are 
not very important for bidders (but there is a long tail with very important tenders). One could therefore ask whether the bidding process is too cumbersome in that respect?

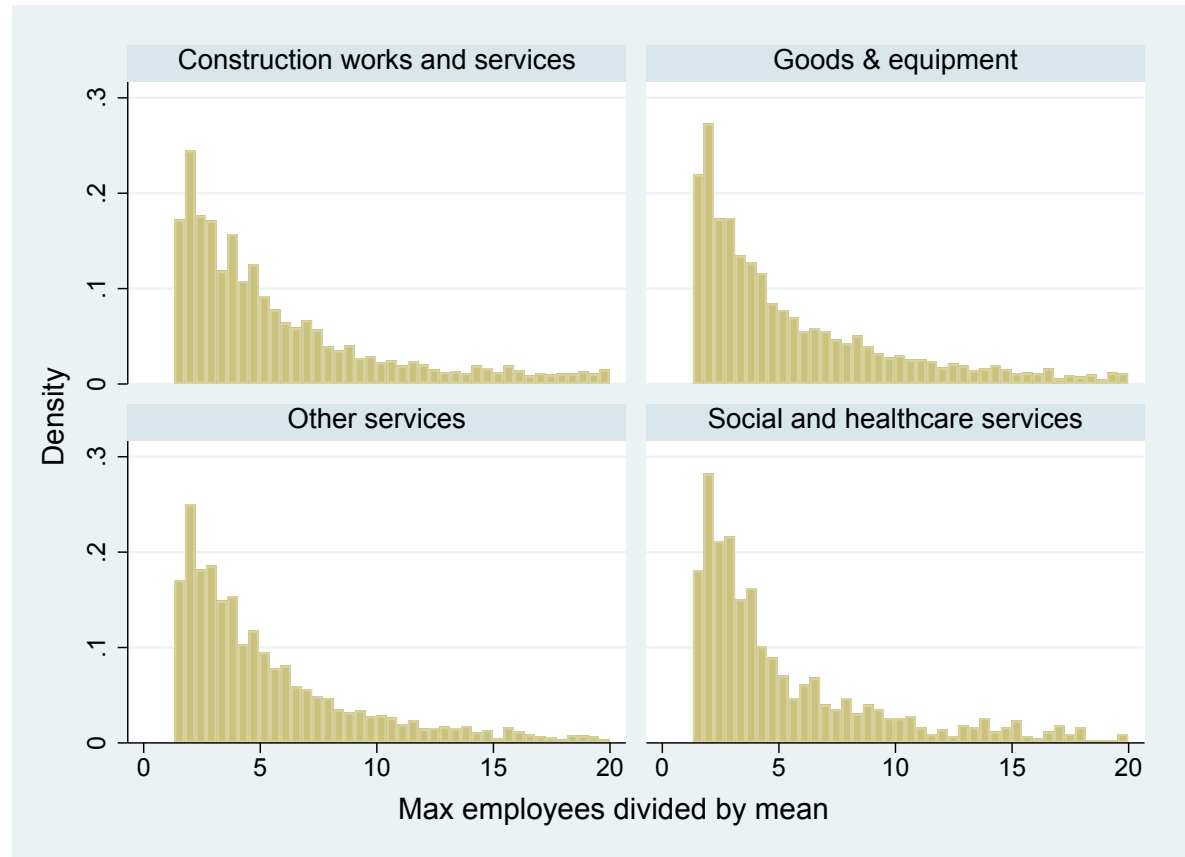

Figure 7: Distribution of bidder heterogeneity in employees

Notes: Bidder heterogeneity is calculated as maximum bidder employee count divided by mean bidder employee count for each invitation to tender. Bidders' employee counts are recorded as an average over the year the ITT took place. Distributions are truncated at 20. The unit of observation is bidder - ITT pair.

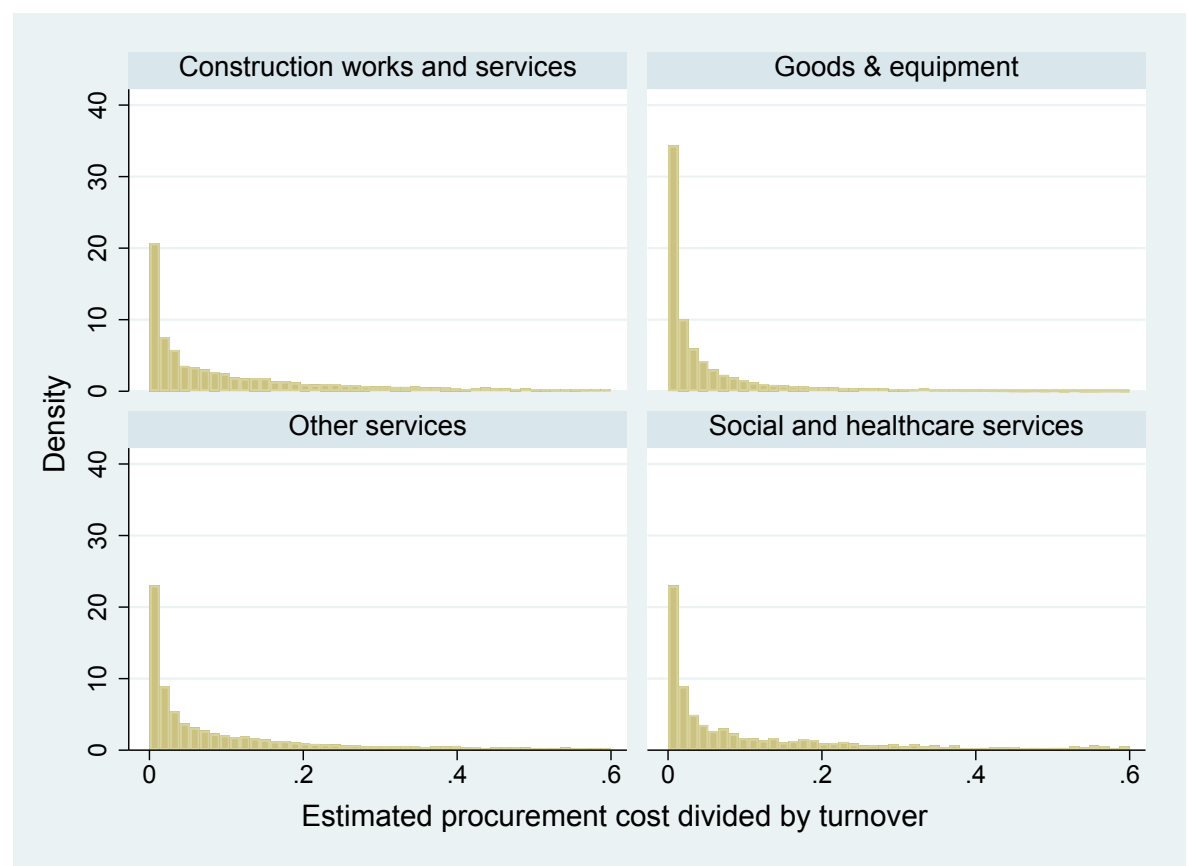

Figure 8: Distribution of procurement's significance to bidders.

Notes: A procurement's significance is calculated as the shares of the estimated procurement costs divided by bidder turnover. This is calculated for each bidder within each invitation to tender. 


\section{Conclusions}

We use unique, comprehensive and rich data on Finnish public procurement to provide a set of stylized facts, some of which the previous literature has not been able to provide. First, we document a serious lack of competition in Finnish PP in general across all industries and procurers. This concern seems not to be limited to Finland as similar observations have been made elsewhere. For example, in Sweden more than half of public procurement contracts received between zero and three bids (Swedish Competition Authority 2017). Similar patterns are observed in Russian (Vitalijs 2017) and Lithuanian data (Baltrunaite 2018), and in the EU in general (European Commission 2017).

Second, the lack of competition is a problem as competition seems to have the desired price implications. Third, the lack of competition results both from potential entrants not actually bidding, but sometimes also from a lack of potential entrants. As such this calls for the contract design to make contracts more attractive and to decrease entry costs. It seems that the use of scoring auctions correlates with less entry, indicating one potential auction rule based remedy, at least if there are other feasible ways to contract for quality. Moreover, a careful scrutiny of optimal reservation prices to limit the adverse effects of competition is needed in any case. However, another consideration is that perhaps not all auctioneers want to engage in attracting more competition, but rather have their favoured producers. In some cases such discretion may be warranted and efficient, but can also be motivated by favoritism or corruption. We leave analysis of procurer motivations for further research.

Finally, the entry patterns in the data seem more consistent with information acquisition models of entry than bid preparation costs models, further implying that making bidding easier may not substantially increase competition. However, if the auctioneer can make it simpler for potential bidders to calculate their production costs, it could be possible to facilitate more competition. 


\section{References}

Alchian, A. A. \& Demsetz, H. (1972). Production, information costs, and economic organization. The American Economic Review, 62(5), 777-795.

Asker, J. \& Cantillon, E. (2008). Properties of scoring auctions. The RAND Journal of Economics, 39(1), 69-85.

Asker, J. \& Cantillon, E. (2010). Procurement when both price and quality matter. The RAND Journal of Economics, 41(1), 1-34.

Balat, J. (2017). Highway procurement and the stimulus package: Identification and estimation of dynamic auctions with unobserved heterogeneity. Working Paper.

Baltrunaite, A. (2018). Political contributions and public procurement: Evidence from lithuania. Forthcoming in Journal of the European Economic Association.

Bandiera, O., Prat, A., \& Valletti, T. (2009). Active and passive waste in government spending: Evidence from a policy experiment. American Economic Review, (4), 1278-1308.

Baranek, B. \& Titl, V. (2018). Political connections and competition on the public procurement market. Working Paper.

Best, M. C., Hjort, J., \& Szakonyi, D. (2018). Individuals and organizations as sources of state effectiveness. Working Paper.

Boas, T. C., Hidalgo, F. D., \& Richardson, N. P. (2014). The spoils of victory: Campaign donations and government contracts in brazil. The Journal of Politics, 76 (2), 415-429.

Bulow, J., Huang, M., \& Klemperer, P. (1999). Toeholds and takeovers. Journal of Political Economy, 107(3), 427-454.

Bulow, J. \& Klemperer, P. (1996). Auctions versus negotiations. The American Economic Review, 86(1), 180-194.

Coviello, D. \& Gagliarducci, S. (2017). Tenure in office and public procurement. American Economic Journal: Economic Policy, 9(3), 59-105. 
Coviello, D., Moretti, L., Spagnolo, G., \& Valbonesi, P. (2018). Court efficiency and procurement performance. The Scandinavian Journal of Economics, 120(3), 826-858.

Decarolis, F., Giuffrida, L. M., Iossa, E., Mollisi, V., \& Spagnolo, G. (2018). Bureaucratic competence and procurement outcomes. Working Paper.

European Commission (2017). Communication from the commission to the european parliament, the council, the european economic and social committee and the committee of the regions: Making public procurement work in and for europe. Strasbourg, 3.10.2017 COM/2017/0572.

Ferraz, C., Finan, F., \& Szerman, D. (2016). Procuring firm growth: The effects of government purchases on firm dynamics. Working Paper.

Gentry, M. \& Li, T. (2014). Identification in auctions with selective entry. Econometrica, 82(1), $315-344$.

Giuffrida, L. M. \& Rovigatti, G. (2018). Can the private sector ensure the public interest? evidence from federal procurement. Working Paper.

Gugler, K., Weichselbaumer, M., \& Zulehner, C. (2015). Competition in the economic crisis: Analysis of procurement auctions. European Economic Review, 73, 35 - 57.

Gulzar, S., Rueda, M., \& Ruiz, N. A. (2018). Kickbacks and limits on campaign donations. Working Paper.

Hart, O., Shleifer, A., \& Vishny, R. W. (1997). The proper scope of government: Theory and an application to prisons. The Quarterly Journal of Economics, 112(4), 1127-1161.

Hong, H. \& Shum, M. (2002). Increasing competition and the winner's curse: Evidence from procurement. The Review of Economic Studies, 69(4), 871-898.

Hubbard, T. P., Li, T., \& Paarsch, H. J. (2012). Semiparametric estimation in models of first-price, sealed-bid auctions with affiliation. Journal of Econometrics, 168(1), 4- 16.

Hyytinen, A., Lundberg, S., \& Toivanen, O. (2018). Design of public procurement auctions: evidence from cleaning contracts. The RAND Journal of Economics, 49(2), 398-426. 
Kang, K. \& Miller, R. A. (2017). Winning by default: Why is there so little competition in government procurement? Working Paper.

Klemperer, P. (2000). Why every economist should learn some auction theory. Available at SSRN: http://dx.doi.org/10.2139/ssrn.241350.

Lee, M. (2017). Government purchases, firm growth and industry dynamics. Working Paper.

Levin, D. \& Smith, J. L. (1994). Equilibrium in auctions with entry. The American Economic Review, 84(3), 585-599.

Lewis, G. \& Bajari, P. (2011). Procurement contracting with time incentives: Theory and evidence. The Quarterly Journal of Economics, 126(3), 1173-1211.

Lewis, G. \& Bajari, P. (2014). Moral hazard, incentive contracts, and risk: Evidence from procurement. The Review of Economic Studies, 81(3), 1201-1228.

Lewis-Faupel, S., Neggers, Y., Olken, B. A., \& Pande, R. (2016). Can electronic procurement improve infrastructure provision? evidence from public works in india and indonesia. American Economic Journal: Economic Policy, 8(3), 258-83.

Li, T. \& Zheng, X. (2009). Entry and Competition Effects in First-Price Auctions: Theory and Evidence from Procurement Auctions. The Review of Economic Studies, 76(4), 1397-1429.

Liebman, J. B. \& Mahoney, N. (2017). Do expiring budgets lead to wasteful year-end spending? evidence from federal procurement. American Economic Review, 107(11), 3510-49.

Marmer, V., Shneyerov, A., \& Xu, P. (2013). What model for entry in first-price auctions? a nonparametric approach. Journal of Econometrics, 176 (1), 46 - 58.

Mironov, M. \& Zhuravskaya, E. (2016). Corruption in procurement and the political cycle in tunneling: Evidence from financial transactions data. American Economic Journal: Economic Policy, 8(2), 287-321.

Myerson, R. B. (1981). Optimal auction design. Mathematics of operations research, 6(1), 58-73.

Niskanen, W. A. (1971). Bureaucracy and Representative Government. Chicago: AldineAtherton. 
Palguta, J. \& Pertold, F. (2017). Manipulation of procurement contracts: Evidence from the introduction of discretionary thresholds. American Economic Journal: Economic Policy, $9(2), 293-315$.

Pinkse, J. \& Tan, G. (2005). The affiliation effect in first-price auctions. Econometrica, 73(1), $263-277$.

Ruiz, N. A. (2018). Power of money. the consequences of electing a donor funded politician. Working Paper.

Samuelson, W. F. (1985). Competitive bidding with entry costs. Economics letters, 17(1-2), $53-57$.

Schoenherr, D. (2018). Political connections and allocative distortions. Journal of Finance, forthcoming.

Straub, S. (2018). Political firms, public procurement, and the democratization process. Working Paper.

Swedish Competition Authority (2017). Statistik om offentlig upphandling 2017. Konkurrensverket rapport 201\%:11.

Vitalijs, J. (2017). Can entry mitigate the effect of inflated reserve prices in public procurement? Working Paper. 


\section{Online appendix}

Table 13: Invitations to tender in our sample and Hilma database

\begin{tabular}{|c|c|c|c|c|c|c|}
\hline \multirow[b]{2}{*}{ CPV classification } & \multicolumn{3}{|c|}{ Whole sample } & \multicolumn{3}{|c|}{ Year 2016} \\
\hline & Hilma & Our sample & Share & Hilma & Our sample & Share \\
\hline Construction contracts & 30887 & 2254 & .07 & 3823 & 527 & .14 \\
\hline Construction services & 8931 & 623 & .07 & 1043 & 174 & .17 \\
\hline Medical equipment & 7728 & 1802 & .23 & 845 & 411 & .49 \\
\hline Social \& Health care & 5067 & 1247 & .25 & 719 & 296 & .41 \\
\hline Transport services & 4755 & 797 & .17 & 567 & 172 & .30 \\
\hline Business services & 4635 & 794 & .17 & 643 & 191 & .30 \\
\hline Environmental services & 4194 & 602 & .14 & 534 & 128 & .24 \\
\hline Transport equipment & 4113 & 847 & .21 & 503 & 184 & .37 \\
\hline Training services & 3833 & 595 & .16 & 488 & 233 & .48 \\
\hline Research services & 3575 & 147 & .04 & 344 & 39 & .11 \\
\hline IT services & 3420 & 388 & .11 & 449 & 116 & .26 \\
\hline Furniture & 3142 & 661 & .21 & 346 & 155 & .45 \\
\hline Construction equipment & 2908 & 400 & .14 & 336 & 92 & .27 \\
\hline Laboratory equipment & 2686 & 254 & .09 & 291 & 68 & .23 \\
\hline Maintenance services & 2649 & 258 & .10 & 338 & 67 & .20 \\
\hline Industrial machines & 2103 & 332 & .16 & 187 & 65 & .35 \\
\hline Office supplies & 1479 & 304 & .21 & 132 & 46 & .35 \\
\hline Real estate services & 1433 & 106 & .07 & 173 & 16 & .09 \\
\hline Electric equipment & 1379 & 185 & .13 & 139 & 39 & .28 \\
\hline IT Software & 1245 & 185 & .15 & 153 & 54 & .35 \\
\hline ICT equipment & 1202 & 175 & .15 & 120 & 31 & .26 \\
\hline Banking services & 1193 & 77 & .06 & 151 & 16 & .11 \\
\hline Energy & 1148 & 82 & .07 & 129 & 10 & .08 \\
\hline Other services & 1111 & 187 & .17 & 117 & 35 & .30 \\
\hline Foodstuffs & 1049 & 204 & .19 & 99 & 30 & .30 \\
\hline Agricultural machinery & 911 & 125 & .14 & 101 & 29 & .29 \\
\hline Hotel and restaurant serv. & 903 & 146 & .16 & 159 & 42 & .26 \\
\hline Hobby tools & 867 & 194 & .22 & 136 & 62 & .46 \\
\hline Agricultural services & 842 & 202 & .24 & 136 & 49 & .36 \\
\hline Clothes & 713 & 172 & .24 & 80 & 38 & .47 \\
\hline Printed matter & 677 & 117 & .17 & 50 & 21 & .42 \\
\hline Argicultural products & 638 & 129 & .20 & 77 & 33 & .43 \\
\hline
\end{tabular}

Notes: Statistics are presented for our whole sample spanning years 2010 - 2017 as well as for year 2016, which is the latest full year in the sample. Hilma database contains all invitations to tender published by Finnish public sector. Hilma database might contain duplicates, so the shares shown are a lower bound. Categories with over 100 observations in our sample are shown. Social \& Health care services include social housing services. 
Table 14: Cross-reference of our sample and Hilma database

\begin{tabular}{|c|c|c|c|c|}
\hline \multirow[b]{2}{*}{ CPV classification } & \multicolumn{2}{|c|}{ Estimated cost } & \multicolumn{2}{|c|}{ Scoring } \\
\hline & Our sample & Hilma & Our sample & Hilma \\
\hline Agricultural machinery & 87 & 77 & .54 & .4 \\
\hline Agricultural services & 4407 & 3729 & .38 & .2 \\
\hline Argicultural products & 391 & 195 & .33 & .28 \\
\hline Aux. transport services & 838 & 258 & .49 & .38 \\
\hline Banking services & 1277 & 598 & .43 & .37 \\
\hline Business services & 945 & 697 & .6 & .38 \\
\hline Chemical product & 482 & 90 & .15 & .17 \\
\hline Clothes & 343 & 139 & .52 & .31 \\
\hline Construction contracts & 1007 & 888 & .13 & .12 \\
\hline Construction equipment & 326 & 165 & .37 & .3 \\
\hline Construction services & 509 & 296 & .56 & .24 \\
\hline Electric equipment & 253 & 126 & .51 & .32 \\
\hline Energy & 4611 & 1729 & .15 & .18 \\
\hline Environmental services & 786 & 314 & .4 & .21 \\
\hline Foodstuffs & 3411 & 659 & .55 & .18 \\
\hline Furniture & 561 & 303 & .5 & .39 \\
\hline Government services & 438 & 134 & .75 & .27 \\
\hline Hobby tools & 319 & 160 & .51 & .28 \\
\hline Hotel and restaurant serv. & 2222 & 644 & .65 & .27 \\
\hline ICT equipment & 788 & 343 & .48 & .37 \\
\hline IT Software & 717 & 246 & .65 & .32 \\
\hline IT services & 714 & 268 & .72 & .29 \\
\hline Industrial machinery & 139 & 91 & .51 & .42 \\
\hline Installation services & 194 & 128 & .36 & .42 \\
\hline Laboratory equipment & 145 & 115 & .61 & .48 \\
\hline Leather and textiles & 315 & 94 & .47 & .46 \\
\hline Maintenance services & 1497 & 1019 & .41 & .25 \\
\hline Medical equipment & 484 & 183 & .73 & .51 \\
\hline Mining & 787 & 131 & .19 & .11 \\
\hline Mining machinery & 203 & 100 & .48 & .3 \\
\hline Office supplies & 2469 & 705 & .44 & .35 \\
\hline Other services & 863 & 447 & .52 & .28 \\
\hline Postal services & 1383 & 856 & .41 & .56 \\
\hline Printed matter & 2465 & 455 & .36 & .13 \\
\hline Public utilities & 758 & 373 & .66 & .6 \\
\hline Real estate services & 366 & 182 & .34 & .32 \\
\hline Recreational services & 302 & 161 & .65 & .29 \\
\hline Research services & 199 & 171 & .72 & .41 \\
\hline Security services & 1251 & 954 & .55 & .48 \\
\hline Social \& Health care serv. & 3179 & 2814 & .37 & .35 \\
\hline Social housing serv. & 22135 & 18215 & .42 & .42 \\
\hline Training services & 615 & 552 & .83 & .14 \\
\hline Transport equipment & 209 & 137 & .54 & .44 \\
\hline Transport services & 1528 & 578 & .28 & .21 \\
\hline Total & 1301 & 863 & .47 & .3 \\
\hline
\end{tabular}

Notes: Cross-reference of Hilma database and our sample using information on usage of scoring rule and the posted estimated value of tender. 
Table 15: Median win margin by industry

\begin{tabular}{l|ll|ll|ll|ll}
\hline \hline bidders & \multicolumn{2}{|c|}{ Construction } & \multicolumn{2}{|c|}{ Goods \& Equipment } & \multicolumn{2}{|c|}{ Other services } & \multicolumn{2}{|l}{ Social \& Healthcare } \\
& obs & median & obs & median & obs & median & obs & median \\
\hline 2 & 4,818 & 0.20 & 17,062 & 0.25 & 6,827 & 0.31 & 1,321 & 0.23 \\
\hline 3 & 4,766 & 0.12 & 16,633 & 0.16 & 6,733 & 0.25 & 1,202 & 0.14 \\
\hline 4 & 4,411 & 0.11 & 10,870 & 0.12 & 4,771 & 0.20 & 605 & 0.12 \\
\hline 5 & 1,824 & 0.10 & 7,310 & 0.11 & 3,976 & 0.18 & 359 & 0.11 \\
\hline 6 & 1,749 & 0.08 & 3,537 & 0.08 & 1,964 & 0.13 & 173 & 0.16 \\
\hline 7 & 1,020 & 0.09 & 2,511 & 0.10 & 1,264 & 0.13 & 125 & 0.08 \\
\hline 8 & 912 & 0.09 & 1,097 & 0.10 & 1,096 & 0.11 & 124 & 0.08 \\
\hline 9 & 657 & 0.08 & 714 & 0.11 & 685 & 0.10 & 119 & 0.04 \\
\hline $10+$ & 1,591 & 0.04 & 1,991 & 0.04 & 4,104 & 0.10 & 866 & 0.06 \\
\hline \hline
\end{tabular}

Notes: Win margin is calculated as a percentage difference between the lowest and the second lowest bid. The unit of observation is auction. 